\title{
La narration, par Majoragius (1569) et Caussin (1619). Introduction, transcription, traduction et
} notes

\section{Lise Charles et Suzanne Duval}

\section{(2) OpenEdition}

Journals

Édition électronique

URL : https://journals.openedition.org/rhetorique/1306

DOI : $10.4000 /$ rhetorique.1306

ISSN : 2270-6909

Éditeur

UGA Éditions/Université Grenoble Alpes

Édition imprimée

ISBN : 978-2-37747-345-8

Référence électronique

Lise Charles et Suzanne Duval, «La narration, par Majoragius (1569) et Caussin (1619). Introduction, transcription, traduction et notes », Exercices de rhétorique [En ligne], 18 | 2022, mis en ligne le 24 février 2022, consulté le 26 février 2022. URL : http://journals.openedition.org/rhetorique/1306 ; DOI https://doi.org/10.4000/rhetorique.1306

Ce document a été généré automatiquement le 26 février 2022.

\section{c) (ㅇ)(2)}

Les contenus de la revue Exercices de rhétorique sont mis à disposition selon les termes de la Licence Creative Commons Attribution - Pas d'Utilisation Commerciale - Partage dans les Mêmes Conditions 4.0 International. 


\section{La narration, par Majoragius (1569) et Caussin (1619). Introduction, transcription, traduction et notes}

Lise Charles et Suzanne Duval

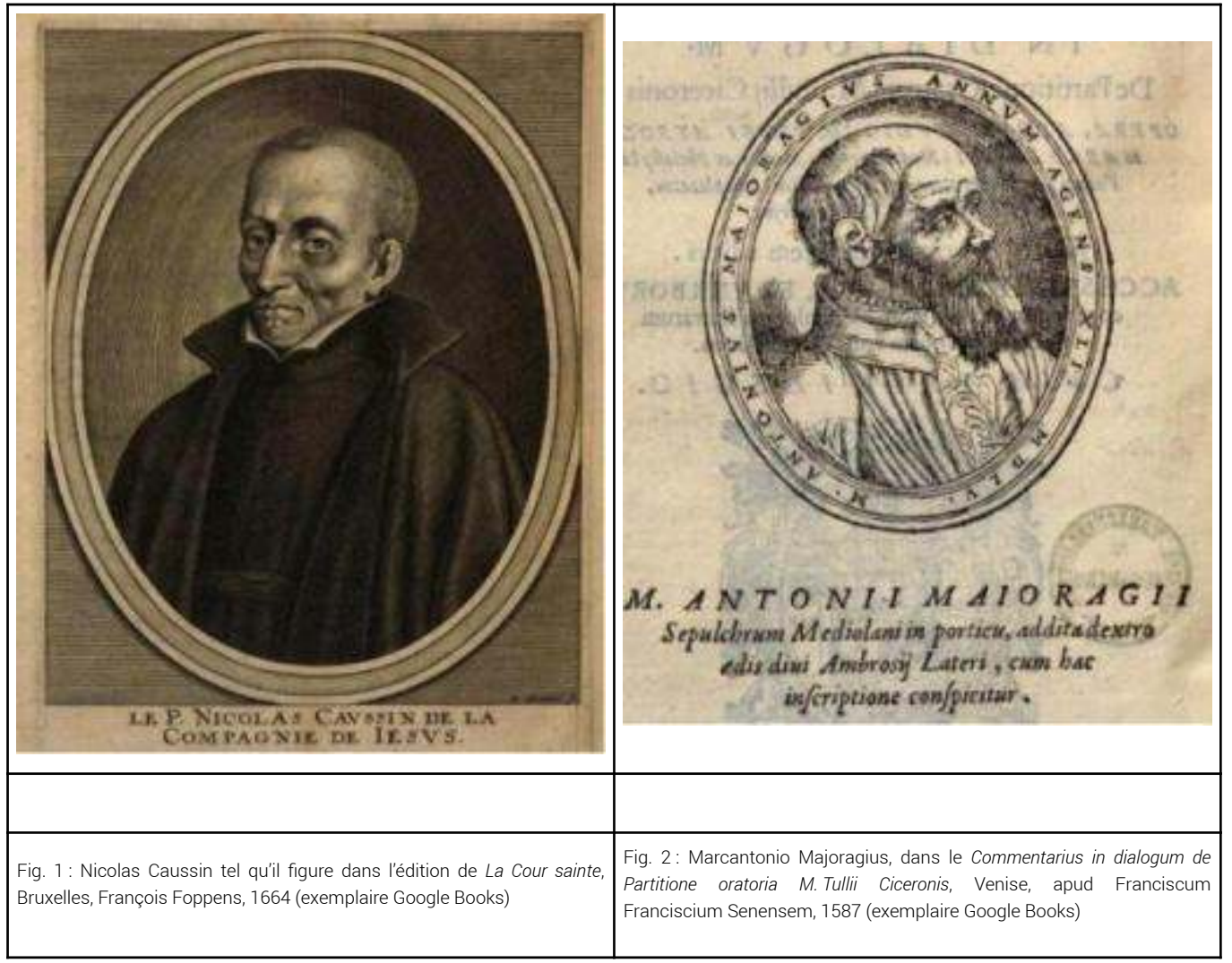




\section{Introduction}

\section{Le traité de Caussin en cachait un autre}

1 Nous aurions aimé offrir à cette livraison de la revue Exercices de rhétorique un traité narratologique du xvII ${ }^{e}$ siècle, écrit en néo-latin, traduit par nos soins et dont l'auteur aurait été Caussin. En lieu et place de cet objet rêvé, notre traduction présente un texte issu de deux auteurs ${ }^{1}$ et de deux siècles différents, sous forme d'une marqueterie de citations, exemples, commentaires, allusions plus ou moins éclaircies et autorisées. Le résultat auquel nous avons abouti n'a donc pas l'efficacité d'une théorie bien faite, mais il offre une somme bien pleine de préceptes et références qui régulent l'art rhétorique de la narration, et rend compte, en outre, d'usages pédagogiques auxquels on ne se serait pas attendu de la part de Caussin.

2 Car nous devons bien avouer que le professeur jésuite ${ }^{2}$, qui nous était d'abord apparu, par son goût des classifications, sa haute culture et son érudition hors normes, comme l'auteur idéal chez qui puiser une synthèse de la narration en rhétorique, nous a un peu déçues. Traduisant les cinq chapitres qui, au sein du sixième livre de L'Éloquence sacrée et profane intitulé "De la disposition et des parties du discours", traitent de la narration, nous n'avons pas retrouvé l'ampleur de style et de vue, la folle recherche d'exhaustivité, le goût pour la diversification polyglotte des références et des exemples accompagnés de leur commentaire sensible, et encore moins la fantaisie érudite qui caractérisaient les chapitres consacrés aux vices de style ${ }^{3}$.

3 Caussin y reprend pourtant la méthode pédagogique qui consiste, après une définition de la notion, à réguler une pratique rhétorique en distinguant ses vices caractéristiques de leurs vertus voisines, conformément au cadre de pensée aristotélicien qui définit la juste mesure comme un équilibre entre deux précipices ${ }^{4}$. Il commence par définir les usages et les différents types de narrations, qui sont au nombre de huit: narration, contre-narration, narration divisée, narration accessoire, narration postérieure, narration pure, narration répétée, construction (chapitre 13). Caussin expose ensuite les huit vices qu'il convient d'éviter dans la narration: prolixité, parenthèses trop nombreuses, ambiguïtés dans la formulation, profusion incontrôlée des personnages, invraisemblance, elocutio négligée, rythme relâché, répétitions lexicales (chapitre 14). Il en vient alors aux principales vertus de la narration : brièveté, clarté, vraisemblance (chapitre 15), avant de consacrer un chapitre entier au développement de la vertu reine qu'est la vraisemblance, et qui doit prendre en compte les quinze éléments suivants : les personnes (point qui est lui-même divisé en onze sous-catégories), le temps, le lieu, les causes, les témoignages, l'opinion commune, l'autorité, la loi, la coutume, la religion, l'honnêteté de l'orateur, la gravité du discours, la mémoire de l'orateur, son habitude de la vérité, la confiance qu'on accorde à sa vie (chapitre 16). Enfin, il réserve un dernier chapitre à une vertu qu'il n'avait pas encore citée, l'agrément ou suavitas, qualité typiquement cicéronienne qui se décline en dix points : l'étonnement, l'attente, les dénouements inattendus, les mouvements pathétiques, les dialogues, la douleur, la colère, la crainte, l'allégresse, les passions (chapitre 17).

4 Dans ces chapitres, Caussin s'écarte du style périodique qui caractérise parfois ses écrits. Il verse dans la sécheresse énumérative et l'accumulation indigeste de catégories théoriques. Il s'en tient au seul Cicéron pour illustrer les bonnes pratiques de la narration par des citations qu'il commente à peine, et oublie de nous amuser en 
s'arrêtant à des exemples de mauvaises narrations pour illustrer ses huit vices. Trouvait-il que la narration n'était pas une partie intéressante de la théorie rhétorique ? Ou considérait-il que tout était déjà dit à son sujet? Ces deux hypothèses nous paraissent vraisemblables depuis que nous avons découvert que Caussin s'était permis de recopier mot pour mot, dans ses chapitres 16 et 17 , un texte antérieur du professeur milanais Majoragius.

Certes, Caussin ne passe pas entièrement sa source sous silence, puisqu'il mentionne Majoragius au début du chapitre 16 portant sur la vraisemblance :

Dans cette espèce, Cicéron énumère quinze causes qui visent la vraisemblance, et celles-ci sont illustrées par Majoragius avec des exemples bien connus, qu'il ne sera pas superflu d'ajouter ici en faveur de la jeunesse ${ }^{5}$.

Mais la citation paraît hâtive, dans la mesure où Caussin ne se contente pas d'emprunter ses exemples à l'ouvrage de Majoragius intitulé Commentaire sur le dialogue des Divisions de l'art oratoire de Cicéron (édité pour la première fois à titre posthume, en 1569): il recopie non seulement les citations tirées des discours de Cicéron par lesquelles Majoragius illustre les quinze caractéristiques de la vraisemblance, mais l'ensemble de la glose de Majoragius. Ce dernier cite et commente le texte suivant de Cicéron :

[La narration] sera vraisemblable, si les choses racontées ne sont pas en contradiction avec les personnes, avec les circonstances de temps et de lieu; si chaque fait, chaque effet reçoit son explication; si ce qu'on dit parât établi par un témoignage appuyé sur l'opinion générale ou sur quelque autorité, conforme aux lois, aux mœurs, à la religion; si le narrateur donne de lui l'idée d'un homme probe, de vieille souche, doué d'une bonne mémoire, qui parle franc et auquel sa vie sert de garant ${ }^{6}$.

Force est de constater que le texte emprunté par Caussin à Majoragius ne se réduit pas à des exemples illustrant les préceptes de Cicéron: Majoragius enrichit par un développement raisonné en quinze points ce qui, de la part de Cicéron, n'était qu'une énumération très resserrée, et il apporte à chacun de ces points une définition et parfois une subdivision qui lui appartiennent. Ainsi, les «personnes" sont divisées en onze sous-catégories richement amplifiées: le nom, la nature, le mode de vie, la fortune, la disposition la morale, les affects, les goûts, les décisions, les actions, les événements inopinés et les propos. Il augmente ces explications de nombreux exemples tirés de divers discours de Cicéron. Si le commentaire de Majoragius ne relève pas à proprement parler d'une interprétation de la source cicéronienne, il n'en met pas moins en œuvre un dispositif pédagogique riche, bien pensé, efficace, et dont Caussin s'est emparé sans préciser l'étendue de son emprunt. La fraude devient encore plus manifeste au chapitre 17, où Caussin recopie le développement de Majoragius sur l'agrément, divisé en dix points. Cette fois-ci, le commentaire du Milanais repose sur la citation suivante de Cicéron :

On trouvera de l'agrément aux narrations qui présentent des passages qui étonnent, qui suscitent l'attente, des dénouements inattendus, par endroits des mouvements pathétiques, des dialogues, de la douleur, de la colère, de la crainte, de l'allégresse, des passions'.

6 Caussin a-t-il considéré que l'œuvre du pédagogue relevait en quelque sorte du bien public et que son commentaire se mettait tellement au service de la théorie cicéronienne qu'il y perdait sa propre autorité, et devenait un simple porte-voix ? Ou bien peut-on parler d'un plagiat pédagogique, au même titre que l'on parle de plagiat littéraire ou universitaire ${ }^{8}$ ? Rappelons qu'en recopiant Majoragius, Caussin ne pillait 
pas l'ouvrage d'un inconnu, mais d'un rhétoricien célèbre dans la République des Lettres, et dont les livres circulaient au sein des collèges jésuites ${ }^{9}$, même s'ils sont aujourd'hui largement oubliés des études rhétoriques françaises ${ }^{10}$.

\section{Marcantonio Majoragius (1514-1555) : une vie de querelles}

Aujourd'hui, Majoragius est un inconnu : il ne sera donc pas inutile de retracer sa vie à grands traits ${ }^{11}$. Il naquit en 1514, près de Milan, à Majoragio. Pendant les guerres de Lombardie, sa famille perdit presque tous ses biens, et son père Giuliano fut emprisonné. La paix revenue, Majoragius reçut une éducation littéraire de son cousin Primo Conti, professeur à Côme. Il fut ensuite accueilli à Milan par Lancellotto Fagnani, et il étudia les mathématiques et la logique. Parmi ses maîtres, on compte Jérôme Cardan (1501-1576). Élève brillant, il fut peut-être nommé professeur d'éloquence vers 1540 , à seulement vingt-cinq ans ${ }^{12}$. Il n'exerça ce métier que pendant deux ans, car de nouvelles guerres interrompirent les activités des professeurs. Il se retira alors à Ferrare, où il étudia la philosophie auprès de Vincent Magius et la jurisprudence auprès d'André Alciat.

8 C'est alors qu'il commença à publier des ouvrages sous le nom de Marcantonio Majoragius, pseudonyme qui lui valut un procès à son retour à Milan ${ }^{13}$. Il dut en effet se défendre devant le Sénat d'avoir changé son nom de baptême, préférant Marcus Antonius Maioragius à Anton Maria de' Conti. Voici un extrait de sa brillante défense, résumée par Bayle comme " un exemple des superstitions de la secte cicéronienne » :

il avoua de bonne foi la raison qui l'avait mu à n'oser paraître en public sous le nom d'Antoine-Marie ; c'est qu'il était si scrupuleux dans le choix des termes, qu'il n'en osait employer aucun, qui ne se trouvât dans les auteurs de la belle latinité. Or il n'y a point d'exemple dans l'antiquité romaine, qu'un homme ait été nommé Marie [...]. Voilà pourquoi il convertit le nom Maria en celui de Marcus, par l'allongement de la dernière syllabe, et le mit devant celui d'Antonius ; car c'eût été une barbarie, un usage inconnu à l'ancienne Rome, que de s'appeler Antonius Marcus. Il fallut donc non-seulement allonger l'un de ses noms, mais aussi lui faire changer de place ${ }^{14}$.

Acquitté, il put continuer un enseignement fondé notamment sur l'usage antique des déclamations, ce qui peut expliquer l'intérêt que lui portèrent les enseignants des collèges jésuites.

Dans les années 1550, il fut au centre d'une querelle sur Cicéron. Après avoir été le défenseur de ce dernier contre Celio Calcagnini, qui avait critiqué les livres des Devoirs (le De Officiis) ${ }^{15}$, ce fut son tour de critiquer les Paradoxes de Cicéron, considérant que ce dernier était bon orateur, mais mauvais philosophe ${ }^{16}$. Ce fut l'origine d'une âpre dispute entre lui et Mario Nizzoli ${ }^{17}$. Ce dernier lui écrivit d'abord une longue lettre amicale, où il lui énumérait les erreurs qu'il avait commises. Majoragius répondit à cette lettre en rédigeant sa propre apologie, à laquelle répondit l'Antapologia de Nizzoli, suivie de près par un long texte de Majoragius contre son adversaire, intitulé Reprehensionum Libri duo contra Marium Nizolium (1549). Nizzoli répondit par son De veris principiis et vera ratione philosophandi contra pseudophilosophos, publié en 1553, et qui commence par une lettre " aux lecteurs contre Majoragius » : « il connaît aussi bien la philosophie qu'un âne la musique ", lit-on par exemple dans ce texte liminaire, tantum scit de Philosophia, quantum asinus de musica. Cette dispute marqua durablement le monde des lettres italien, à qui il déplaisait de voir deux doctes personnages irrités l'un contre l'autre. Comme l'écrit Tiraboschi en conclusion de son article : «C'est la seule tache qui obscurcisse un peu la 
renommée d'un auteur si valeureux, qui, par l'élégance, l'éloquence et l'érudition peut être mis au même rang que les meilleurs du $\mathrm{XvI}^{\mathrm{e}}$ siècle $^{18}$ ». Notons que la dispute fut réactualisée par Leibniz: il publia en effet en 1674 une nouvelle édition du De veris principiis, précédé d'une préface, Dissertatio Praeliminaris de Instituto Operis atque optima philosophi Dictione, où il montrait l'importance de Majoragius, et soulignait que les deux polémistes avaient en commun le désir de réformer la philosophie ${ }^{19}$.

Élevé en 1550 à une dignité ecclésiastique, Majoragius n'en profita pas longtemps, car il mourut en 1555, à quarante ans. Citons, comme une mise en garde à nos collègues, l'hypothèse de Bayle sur les causes de la mort de Majoragius : " Il continua d'enseigner avec une forte application, qui sans doute lui abregea la vie ${ }^{20} »$. Son titre de gloire reste la traduction en latin de la Rhétorique d'Aristote, très bien reçue au XVII siècle, et le commentaire qui l'accompagne, les Explanationes ${ }^{21}$. Il n'est donc pas surprenant que, pendant ses années de jeune enseignant au Collège de la Trinité à Lyon, ClaudeFrançois Menestrier mentionne expressément Majoragius à ses élèves de rhétorique, à la fin d'une liste qu'il leur dicte des auteurs « nouveaux qui enseignent la rhétorique »: «[...] Vossius, Maioraggio qui a excellemment commenté la rhétorique d'Aristote, Caussin, l'auteur du Palais de l'Éloquence ${ }^{22}$."

11 Chose amusante, Bayle conclut son article, dans la troisième édition de son dictionnaire, par une formule lapidaire: "Majoragius doit être mis dans le catalogue des personnes accusées de plagiat ». Il raconte en effet qu'il aurait plagié Pier Vettori dans un commentaire d'Aristote. Mais, de même que nous hésitons à parler de plagiat pour Caussin, qui pille Majoragius tout en citant son nom, tous n'étaient pas d'accord pour accuser Majoragius de cette fraude :

Un docte Allemand me paroît justifier fort bien Majoragio de cette accusation. Il observe d'abord que Bayle l'a condamné avec trop de précipitation, \& que Natalis Comes n'a pas dit ce qu'il lui fait dire. Il prétend que ce dernier, quoiqu'il traite fort durement Majoragio, ne l'accuse en aucune façon de plagiat. Quoi! dit-il, si Majoragio s'est servi de plusieurs remarques de Victorius, doit-il être censé les lui avoir dérobées? Il y a deux manières de puiser dans un Ecrivain; l'une, sans le citer, \& l'autre, en le citant. La dernière est permise ; \& c'est celle qu'a employée Majoragio. Le récit de Natalis Comes pourroit faire croire, à la vérité, que Majoragio avoit entre les mains quelques Ecrits de Victorius, qui n'avoient point été rendus publics, \& dont il auroit fait usage comme des siens propres, sans que ce vol littéraire fût venu à la connoissance de qui que ce soit, à l'exception d'un petit nombre de personnes. Mais il n'y a que ceux qui ne sont point instruits des Ouvrages de Victorius \& de Majoragio, qui puissent penser de la sorte. Voici comment la chose se passa. L'un \& l'autre prirent le dessein d'éclaircir la Rhétorique d'Aristote. Le Commentaire de Victorius parut à Venise en 1548. [...] Majoragio, enchanté de la beauté \& de l'érudition de cet Ouvrage, en tira un grand nombre d'obversations, dont il enrichit le sien. Mais il ne le fit point sans nommer Victorius $^{23}[\ldots]$.

\section{Un art de narrer cicéronianiste}

12 Le commentaire de Majoragius sur les Divisions de l'art oratoire atteste de sa connaissance profonde de l'œuvre de Cicéron, puisque l'orateur romain offre non seulement la théorie, mais aussi les modèles de la narration, certaines citations de ses discours étant d'ailleurs utilisées plusieurs fois pour illustrer différents points. Ainsi, cette caractérisation de Milon: "visant moins à atteindre un degré dans la série des dignités, ce qui est l'ambition de tous les autres, qu'à éviter d'avoir pour collègue un 
homme de haute valeur morale ${ }^{24}$ ", sert d'exemple non seulement pour l'air antique de l'orateur, mais aussi pour la représentation des décisions de la personne inculpée. Les deux plaidoyers que Majoragius cite le plus souvent sont celui pour Roscius d'Amérie et celui pour Cluentius, c'est-à-dire, respectivement, un discours de jeunesse et un autre de maturité. La défense de Sextus Roscius accusé de parricide fut en effet la première causa publica de Cicéron, alors âgé de vingt-sept ans. Il mentionne son succès tout en critiquant son propre discours dans L'Orateur : «Quelles acclamations quand dans notre prime jeunesse nous avons dit, sur le supplice des parricides, ces choses dont nous n'avons commencé qu'un peu plus tard de comprendre qu'elles n'avaient pas suffisamment achevé leur fermentation ${ }^{25}$ ». Dans ce même passage de L'Orateur, il loue au contraire les "paroles désormais mûres ${ }^{26}$ » du plaidoyer pour Cluentius. De fait, Cicéron avait quarante ans au moment du procès où il prit la défense de Cluentius, dans un discours qui fut souvent l'objet d'éloges dans l'Antiquitée ${ }^{7}$. Serait-ce l'opposition faite par Cicéron qui aurait poussé Majoragius à choisir de préférence ces deux discours, dans le but de varier les exemples et les styles au sein même du corpus cicéronien ? Il n'explicite pas les raisons de son choix.

Le développement de Majoragius que nous avons traduit traite des vertus de la narration, et la tripartition annoncée, en suivant Cicéron, rassemble la clarté, la vraisemblance et l'agrément. Un peu plus loin, une autre tripartition est présentée : clarté, brièveté et vraisemblance («tres aiunt esse narrationis uirtutes, ut dilucida sit, ut breuis, ut probabilis »), mais, de fait, c'est sur la vraisemblance et l'agrément que Majoragius s'attarde le plus. Caussin, dans sa réécriture, fusionne les deux tripartitions, et propose de considérer les quatre vertus que sont la brièveté, la clarté, la vraisemblance et l'agrément, en consacrant à ces deux dernières deux chapitres séparés.

14 La narration est "l'assise et le fondement " (sedes et fundamentum, l'expression est employée à plusieurs reprises) de la confiance qui doit être établie afin que la confirmation soit efficace. Or, sans vraisemblance, la confiance est impossible. Il s'agit donc de la vertu la plus importante de la narration. Majoragius (comme plus tard Caussin) emploie le même mot que Cicéron, celui de probabilitas, avec l'adjectif probabilis, sauf une fois, où il lui préfère l'adjectif uerisimilis ( « nam, ni uerisimilis narratio sit...»), qui fonctionne ici comme un synonyme parfait. Quintilien lui-même avait observé cette tendance du vocabulaire de la narration à la profusion des synonymes :

La plupart des théoriciens, et surtout les Isocratiques, veulent qu'elle soit claire [lucidam], brève [breuem], vraisemblable [ueri similem]. Peu importe en effet qu'au lieu de «claire» nous disions transparente [perspicuam], au lieu de « vraisemblable » « plausible» [probabilem] ou « croyable» [credibilem] ${ }^{28}$.

La vraisemblance invoquée par Majoragius et Caussin est fondée sur la stricte convenance de l'ordonnancement de la narration avec les croyances du public : il s'agit donc d'une vraisemblance rhétorique, et non poétique ${ }^{29}:$ plus qu'à la cohérence interne $\mathrm{du}$ temps, des personnages et des actions de la diégèse, c'est surtout à l'opinion de son public que l'orateur doit être attentif, de manière à ne pas le choquer.

Tout se passe comme si la res qui était traitée dans la narration, à la différence de la fiction aristotélicienne, contenait déjà en elle-même un ordre et un agencement sur lequel l'orateur a assez peu de marge de manœuvre. Mais des choix se présentent tout de même à lui : se concentrer uniquement sur la narration de l'affaire, ou mettre l'accent sur les circonstances, voire insérer des digressions; insister ou non sur les passages qui suscitent la suauitas - terme délicat à traduire, que nous avons choisi de 
rendre par agrément, en raison de son extension chez nos auteurs. Notons que, parmi les dix éléments qui suscitent l'agrément, certains ne dépendent pas de l'orateur (il ne lui appartient pas, par exemple, que son dénouement soit imprévu et heureux), d'autres concernent le degré de précision et d'amplification du discours (ainsi, l'orateur peut choisir de faire figurer des dialogues, ou de les passer sous silence), et d'autres enfin sa disposition (l'orateur peut retarder un moment crucial de la narration afin de susciter l'attente). À lire les nombreux conseils de Majoragius sur les manières de rendre la narration agréable, on se demande parfois comment la breuitas s'accommode de la suauitas.

\section{Où l'on retrouve l'humour de Nicolas Caussin}

16 Au regard de l'orthodoxie cicéronienne de Majoragius, Caussin opère une ouverture des modèles... et perd en clarté et brièveté. Ainsi, en se fondant sur l'Ars rhetorica de Fortunatianus, rhétoricien romain $\mathrm{du} \mathrm{IV}^{\mathrm{e}}$ siècle, il détaille huit espèces de narration: " Paradiégèse ", « hypodiégèse ", « catadiégèse ", « épidiégèse "... On se croirait parfois face à une parodie d'un ouvrage de Gérard Genette, et nous avons délibérément choisi de ne pas adoucir dans notre traduction des calques du grec qui devaient être rudes à l'oreille de Caussin et de ses lecteurs. On pense à Aristote, qui dans sa Rhétorique écrivait qu'« on ne doit instituer de nom que pour désigner une espèce ou une variété, sous peine de tourner à vide dans le délire verbal» (III, 13, 1414b14). Mais Caussin en est conscient et traite d'emblée ces catégories avec distance : «Il existe huit espèces de narration, qui ont été inventées par les rhéteurs chicaneurs, et comme d'habitude excessifs à bien des égards. » De cette longue énumération, il ne tire pas grand profit, au point que l'on peut se demander si la conclusion de son énumération, «Tout cela clarifiera l'usage de la narration ", n'est pas ironique. Décidément, le professeur jésuite semble avoir rédigé ses chapitres sur la narration avec un certain manque de sérieux... ou un peu de fatigue? Dans sa correspondance, le médecin et Doyen de la Faculté de médecine de Paris Guy Patin témoigne des difficultés que Nicolas Caussin pouvait rencontrer avec ses imprimeurs :

On imprime ici le livre latin in- $\mathrm{f}^{\circ} \mathrm{du}$ P. Caussin; celui de la Cour sainte est véritablement plein de rhapsodies, et principalement aux $3^{\mathrm{e}}$ et $4^{\mathrm{e}}$ tome. Ce fut l'avarice du libraire qui pressa ce bon père d'augmenter le nombre de ces volumes afin de gagner davantage ; et néanmoins le bonhomme était épuisé, il avait mis tout ce qu'il savait de bon dans les deux premiers tomes ${ }^{30}$.

\section{Principes d'édition}

Nous avons donc choisi de présenter successivement les chapitres de Caussin sur la narration qu'il n'a pas recopiés sur Majoragius, ceux de Majoragius que Caussin n'a pas recopiés et enfin ceux de Majoragius que le Jésuite a recopiés, moyennant de très minimes modifications que nous avons signalées (abrègement des exemples, quelques lignes conclusives sur la suauitas).

Pour le texte latin de Caussin, nous éditons les chapitres XI, XIII et XIV de l'édition originale de 1619 (N.Caussin, Eloquentiae sacrae et humanae parallela libri XVI, Paris, S. Chapelet, p. 223) tirés du livre VI qui porte sur la disposition.

19 Pour le texte latin de Majoragius, nous éditons une partie (p. 148-155) du Commentaire sur le dialogue des Divisions de l'art oratoire de Cicéron (Antonii Maioragii, in dialogum de 
partitione oratoria M. Tulii Ciceronis, commentarius, ad Petrum Galesinum) paru en 1569 à Milan chez Pacificus Pontius. Il s'agit apparemment de l'édition princeps, parue à titre posthume (alors que la critique présente souvent celle de 1587 comme la première).

Dans notre transcription des textes latins, nous conservons la ponctuation des éditions d'époque, ainsi que les italiques utilisés par Majoragius et Caussin pour mettre en évidence le contenu d'une citation, mais supprimons les crochets que Caussin utilise parfois pour citer un autre auteur. Nous ne gardons pas non plus les italiques dont il use pour les mots grecs. En ce qui concerne les graphies, nous supprimons les accents, remplaçons l'esperluette par et, les lettres ramusiennes $v$ et $j$ par $u$ et $i$ (à l'exception du $V$ majuscule) et les lettres liées par ae et oe.

Dans notre traduction, nous avons voulu mettre en évidence les citations que les éditions d'époque ont tendance à rendre peu repérables. Très souvent, aucune indication typographique n'indique chez Caussin qu'on a affaire à une citation : nous introduisons donc, chez lui comme chez Majoragius, des guillemets français; ils seront toujours de notre fait. Nous conservons également chez Caussin et Majoragius les italiques des citations (transposées ici en romain), ainsi que celui des calques grecs de Caussin (que dans la transcription nous n'avons pas gardés, comme nous l'avons dit).

Pour la traduction de ces citations, nous nous sommes appuyées sur les éditions critiques des Belles Lettres, que nous avons parfois modifiées en signalant notre intervention.

Nous remercions vivement Francis Goyet et Christine Noille, qui ont relu attentivement notre traduction et cette introduction : leurs interventions ont éclairci plusieurs points obscurs et ont enrichi notre commentaire.

\section{Édition}

\section{Chapitres de Caussin non recopiés sur Majoragius}

[Nicolas Caussin, Eloquentiae sacrae et humanae parallela libri XVI, Paris, Sébastien Chapelet, 1619, livre VI, chapitres XIII, XIV et XV, p. 222-223.]

\section{Chapitre XIII. Division et usage de la narration / Cap. XIII. Narrationis diuisio, et usus}

[222a] Avant d'approfondir les règles de la narration, je m'attarde au seuil de cet examen, afin d'éviter les ambiguïtés lexicales. En effet, beaucoup ${ }^{31}$ ont restreint le sens du mot narration à l'exposition d'un fait judiciaire et de l'état de la cause, comme un meurtre, un vol, un sacrilège, etc., si bien que leurs règles au sujet des narrations sont souvent pauvres, et limitées au domaine du seul genre judiciaire. Mais il faut noter la remarque de Quintilien : ne confondons pas la narration de la cause et la narration de tout ce qui se rapporte à la cause ${ }^{32}$.

Antequam ad narrationis praecepta progrediar longius tantisper subsisto in limine: quo uerbi distinguam ambiguitatem. Plerique enim narrationem in eas angustias adduxerunt, ut id solum esse uellent, quod facti ciuilis, statusque caussae, ut caedis, ut furti, ut sacrilegii, et caet. expositionem complecteretur, quo fit ut eorum de narrationibus praecepta tenuia saepe sint, et inter unius iudicialis generis fines contenta. Verum notatione dignum est, quod 
obseruat Quintilianus aliud esse narrationem caussae, aliud eorum, quae pertinent ad caussam. moment de parler des vols de Seius ${ }^{39}$, vous disséminez plusieurs remarques au sujet de sa voracité, son intempérance, et ce qui alimente pour ainsi dire sa rapacité.

Quarta est $\pi \alpha \rho \alpha \delta i \eta ́ \gamma \eta \sigma \iota$, quae aliquas res gestas extra caussam positas inducit, ad confirmationem tamen caussae non inutiles, ut si dicturus de Seii furtis, nonnulla de eius ingluuie, et intemperantia, quasi rapacitatis fomite differas ${ }^{40}$. 


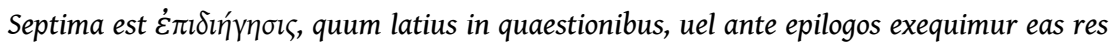
gestas, quas in narratione breuiter attingimus ${ }^{44}$. Hellade $^{49}$, elle se mesure surtout selon les choses, et non selon le nombre de vers ou de mots. On parle de prolixité quand on n'arrive pas à raconter d'une manière mâle [uiriliter], mais qu'à la manière d'un fleuve inerte, on roule difficilement de la boue et de la fange dans des eaux sales : on commence à raconter les événements depuis l'origine [ab ovo], alors que cela ne sert à rien, et on continue en ajoutant des choses froides et vaines, ce qui produit un discours languissant et engourdi, qui ne va pas sans ennui.

Primum, est prolixitas, quam, ut ait D. Gregor. Nazianz. Ad Helladium rebus metiri maxime oportet, non uersibus, aut uerbis : haec fit, ubi quis se uiriliter expedire non potest, sed ut 
iners fluuius lutum, et coenum turbidis aquis aegre uolutat : res quaerit ab ouo, ubi nihil est opus, frigida, et otiosa adiuncta consectatur, quae languida, et iacenti oratione non sine taedio prosequitur. discours hors de son propos et l'égarent, non sans de nombreuses inepties.

Secundum, Parentheses crebrae, et longae, quae sermonem institutum alio trahunt, distrahuntque non sine multis ineptiis.

Le troisième est l'ambiguïté des mots et des phrases, par exemple : "On dit que de Pyrrhus l'armée a triomphé ${ }^{50}$ : comment savoir qui est le vainqueur, qui est le vaincu?

Tertium, ambiguitas uerborum, sententiarumque, ut si quis dicat, aiunt Pyrrhum Romanos hoc praelio fudisse. Quis inde uictor, quis uictus intelligi potest?

Le quatrième est la foule des personnages, la multitude des choses et la confusion qui, dressées d'un coup contre l'intelligence, embrouillent l'esprit de l'auditeur. Il faut étendre la narration de manière progressive, sans en rassembler tous les membres dans un seul nœud.

Quartum, nimia personarum, rerumque multitudo, et confusio, uno ueluti impetu sensibus obiecta, animum confundit auditoris. Distendere oportet paulatim narrationem, nec omnia eiusdem membra in nodum contrahere.

Le cinquième réunit tout ce qui est incroyable et ressemble à une fable, contre la nature commune, les mœurs, les raisons et manières d'agir.

Quintum, quicquid incredibile, et fabulis simile praeter communem naturam, praeter morem, et rationes, atque uias agendi.

[223a] Le sixième est la formulation humble [plutôt : pauvre], obscure, impropre.

Sextum, Dictio humilis, obscura, impropria.

les mots $^{52}$

Septimum, Dissolutio sine ullo decore, nexu, et articulis.

Le huitième est la répétition fréquente et maladroite du même mot.

Octauum, Eiusdem uerbi crebra, et inepta repetitio.

\section{Chapitre XV. Les vertus de la narration / Cap. XV. Narrationis uirtutes}

$\mathrm{Au}$ contraire, les vertus parent la narration.

Contra, Narrationem decent uirtutes.

La première vertu est une brièveté que rien n'alourdit, dans laquelle cependant rien ne semble incomplet, saccadé ni raccourci, et où l'on ne pense pas que vous représentez sans cesse à tes auditeurs les tableaux de Timanthe ${ }^{53}$, dans lesquels il y avait plus à comprendre, que ce qui était peint ; si vous voulez être compris, il faut narrer ; mais attention à ne pas recourir ici avec trop d'affectation à de longues périodes, quand elles ne sont pas nécessaires; on obtiendra une excellente brièveté "par l'emploi de mots simples, quand on n'exprime chaque idée qu'une fois et qu'on ne s'attache à l'idée que pour l'exprimer clairement ${ }^{54}$.»

Prima, expedita breuitas, in qua nihil tamen mancum, nihil concisum, \& decurtatum uideatur, neque enim putes te semper Timantis tabulas auditoribus obiicere, in quibus plus intelligendum erat, quam pingeretur; si uis intelligi, narrare oportet, sed caue, ne longas periodos, ubi nihil opus est, curiosius hic affectes; breuitas percommoda conficietur simplicibus uerbis, semel unaquaque re dicenda, nulli rei, nisi ut dilucide dicas seruiendo. 
deuxième vertu est la clarté, par laquelle le discours coule comme un cours d'eau transparent: il faut pour l'obtenir «employer des mots usuels, pris dans leur sens propre, bien placés, qu'ils soient dans une période parfaite, des phrases coupées ou de brèves incises ${ }^{55} \%$.

Secunda perspicuitas, qua oratio, ut pellucidus amnis fluit, et ea fit usitatis uerbis, propriis, dispositis, aut circumscriptione conclusa, aut intermissa, aut concisione uerborum.

La troisième est la vraisemblance dans le genre de discours utilisé, quand le discours « n'est pas trop peigné ni travaillé, les mots ont de l'autorité et du poids, les pensées sont fortes ou bien adaptées soit à l'opinion soit au caractère des auditeurs ${ }^{56}$. »

Tertia, probabilitas est in genere, si non nimis compta oratio, atque expolita, si est authoritas, et pondus in uerbis, si sententiae, uel graues, uel aptae opinionibus hominum et moribus.

\section{Texte de Majoragius non copié par Caussin}

[M. Antonii Maioragii, in dialogum de partitione oratoria M. Tulii Ciceronis, commentarius, ad Petrum Galesinum, Milan, Pacificus Pontius (Pacifico Poncio ou da Ponte), 1569, p. 148-150. Le commentaire traite ici des Divisions de l'art oratoire de Cicéron, IX, 31-32.]

51 [p. 148] «F. Et dans la narration, quelles règles faut-il observer? P. La narration est l'explication des faits; c'est sur elle pour ainsi dire que l'on se repose et s'appuie pour établir la conviction; il faut donc avant tout observer les mêmes règles que dans les autres parties du discours; les unes sont indispensables, les autres accessoires et d'ornement. La narration sera claire et vraisemblable; cela est indispensable ; accessoirement nous ajouterons l'agrément ${ }^{57}$. "

C. F. Quid in narratione, quae tandem conseruanda sunt ? C. P. Narratio est rerum explicatio, et quaedam quasi sedes, ac fundamentum constituendae fidei : ea sunt in ea seruanda maxime, quae etiam in reliquis fere dicendi partibus, quae partim sunt necessaria, partim assumpta ad ornandum. Nam ut dilucide probabiliterque narremus, necessarium est, sed assumimus etiam suauitatem.

[p. 149] La deuxième partie du discours, que Cicéron traite maintenant, est la narration. Comme la logique le demande, il commence par la définir, avant d'expliquer ce qui doit être respecté lorsque l'on en fait une. Voici donc la définition de la narration: «La narration est l'explication des faits ; c'est sur elle pour ainsi dire que l'on se repose et s'appuie pour établir la conviction ».

Secunda pars orationis est narratio, de qua iam tractare incipit, atque illam, ut artis ratio postulat, primo definit, deinde docet, quid in ea seruandum sit. Definitio igitur narrationis haec est, Narratio est rerum explicatio, et quaedam quasi sedes ac fundamentum constituendae fidei.

En effet, les orateurs n'ont recours à la narration que pour expliquer de quoi il s'agit et, en l'expliquant, semer quelques graines des arguments qui servent de fondement à l'ensemble de la confirmation. Car la confirmation commence avec la narration ellemême. Sans elle, non seulement la cause ne peut être confirmée, mais elle ne peut pas même être comprise. C'est pourquoi elle est toujours nécessaire dans les controverses judiciaires, sauf quand la chose est si connue qu'il n'est pas important de l'expliquer mieux.

Neque enim alia de causa narratione utuntur oratores, nisi ut res eas, de quibus agitur, explicent, atque in explicando semina quaedam argumentationum spargant, quae sint 
tanquam totius confirmationis fundamenta. nam initium confirmationis est ipsa narratio. Sine qua non modo confirmari causa non potest, sed ne intelligi quidem, itaque semper in iudicialibus controuersiis est necessaria, nisi quando res ita peruulgata est, ut eam explicare nihil ultra referat.

Mais il faut respecter dans la narration les mêmes principes que dans les autres parties du discours. En effet, certains préceptes sont communs à toutes les parties : ce sont ceux qui concernent la clarté [claritatem] et la vraisemblance [probabilitatem] du discours, et même ceux qui concernent son agrément [suauitatem]. On peut pourtant les distinguer, car certains sont nécessaires et ne doivent jamais être oubliés, comme la transparence ${ }^{58}$ [ perspicuitas] et la vraisemblance, tandis que d'autres, comme l'agrément, servent à orner le discours sans être pour autant nécessaires.

Eadem uero sunt in narratione seruanda, quae etiam in reliquis orationis partibus. sunt enim quaedam praecepta omnium partium communia, quae ad claritatem, et probabilitatem orationis pertinent, quaedam etiam ad suauitatem. Siquidem haec ita distincta sunt, ut alia sint necessaria, quae nunquam omitti debent, ut perspicuitas, et probabilitas; alia uero assumpta ad ornandum, ut suauitas, quae tamen non sunt necessaria.

Quintilien estime que l'on doit orner la narration de tous les charmes et agréments possibles, car c'est là que le juge est le plus attentif, et rien de bien dit ne se perd; mieux : ce dernier croit plus volontiers les choses qu'il entend avec plaisir ${ }^{59}$. Mais dans ce passage, il traite à notre avis de la narration judiciaire ${ }^{60}$.

Quintilianus existimat, narrationem omni qua potest uenere, et gratia ornandam, quoniam nulla in parte attentior est iudex, et nihil recte dictum perit, quin facilius credit, quae iucunda sunt. Hoc autem loco de ciuili narratione intelligimus.

Il existe en effet trois genres de narrations, comme en témoigne Aphtonios ${ }^{61}$ : la narration historique, qui explique les choses véritables, qu'on nomme les histoires; la narration dramatique, à laquelle recourent les fables, les comédies et les tragédies; la narration politique, qui concerne les procédures civiles.

nam tria narrationum genera sunt, ut Aphtonius testis est, historicum, quo res uerae explicantur, quae historiae nominantur; Drammaticum, quo fabulae, et comoediae, atque tragediae utuntur; Politicum, quod ad causas ciuiles pertinet.

57 Ce dernier genre se divise en deux catégories, comme l'enseigne Cicéron : « la première ne contient que la cause et toute la raison de la controverse. La seconde insère une digression prise en dehors de la cause, et sert à accuser, à comparer, à amuser (mais sans s'éloigner du sujet dont on débat), ou encore à amplifier ${ }^{62}$ ».

Atque hoc ciuile narrationis genus duas habet partes, ut docet Cicero, unam in qua causa, et omnis ratio controuersiae continetur; alteram, in qua digressio aliqua extra causam, aut criminationis, aut similitudinis, aut delectatione, non alienae ab eo negocio, de quo agitur, aut amplificationis causa interponitur.

Souvent, en effet, dans un même discours sont employées plusieurs narrations; mais généralement, il y en a une qui est la principale, c'est celle qui embrasse toute la cause, et dont nous parlons ici.

Saepe enim in una oratione plures narrationes adhibentur; sed una solet esse principalis, quae totam causam continet, de qua hoc in loco intelligimus.

Dans cette narration interviennent presque toujours six éléments, qu'on appelle généralement les « circonstances ", à savoir la personne, la chose, la cause, le lieu, le temps, la manière, comme dans la narration du Pour Milon, qui commence par la personne: «Clodius était décidé à tourmenter l'État durant sa préture par tous les crimes possibles ${ }^{63}$ ». Est alors exposée la chose, c'est-à-dire l'affaire : «La veille, luimême quitta Rome à l'improviste ${ }^{64} »$. Cicéron mentionne beaucoup de causes, mais 
surtout celle-ci : «Il était clair pour lui que sa préture serait infirme et paralysée avec un consul tel que Milon ${ }^{65}$ ». Là, il note le lieu: "pour organiser, devant un de ses domaines, un attentat contre Milon ${ }^{66}$ ». Il explique même le temps : «La rencontre avec Clodius eut lieu devant un domaine de celui-ci, à la onzième heure, ou peu s'en faut ${ }^{67}$. " Enfin, il pose la manière: "Aussitôt une troupe nombreuse de gens armés, d'un lieu dominant, se précipitent sur Milon ${ }^{68} »$.

Huic autem narrationi sex illae fere semper accident, quae uulgo circunstantiae dicuntur, persona, res, causa, locus, tempus, modus, ut in narratione pro Milone, A persona incipit, P. Clodius cum statuisset omni scelere, in praetura uexare Remp. Rem, id est negocium factum exponit. Roma subito ipse profectus pridie est. Causas multas affert, sed illam praecipue, Occurrebat mancam ac debilem praeturam suam futuram consule Milone. locum ibi notat, ut, Ante fundum suum Miloni insidias collocaret. Tempus etiam explicat. Fit obuiam Clodio ante fundum eius hora fere undecima, aut non multo secus. Modus denique ponitur, Statim complures cum telis in hunc faciunt de loco superiore impetum.

Ces mêmes éléments doivent être soigneusement observés dans les autres narrations aussi ; le cas échéant, ils rendent la narration claire et vraisemblable, deux qualités nécessaires, comme l'exprime ici Cicéron :

Atque haec eadem in aliis etiam narrationibus diligenter obseruari solent, quae si commode tractentur, dilucidam et probabilem narrationem efficiunt, quae duo sunt in ea necessaria, ut hoc loco sentit Cicero.

61 "Donc, pour faire une narration claire, nous reprendrons les préceptes donnés plus haut sur la clarté et l'éclat du discours ; il s'en trouve également sur la brièveté, qui fait très souvent le principal mérite de la narration ${ }^{69}$.»

Ergo ad dilucide narrandum eadem illa superiora explicandi, et illustrandi praecepta repetemus, in quibus est brevitas: eaq. saepissime in narratione laudatur, de qua supra dictum est.

[p. 150] On dit qu'il y a trois vertus de la narration : il faut qu'elle soit claire, brève, vraisemblable, qualités qu'il convient de faire briller dans l'ensemble du discours, mais qui sont particulièrement requises dans la narration, parce que celle-ci est comme le siège, et le fondement de la confiance qu'il faut établir. Mais plus haut, comme il traitait des lumières du style, Cicéron a déjà montré par quels moyens rendre le discours clair, bref et vraisemblable. Aussi faut-il reprendre ces préceptes ici. En effet, la narration sera rendue claire, si outre ce qui a été mentionné ci-dessus, l'ordre des faits et la chronologie sont conservés, et si rien n'est formulé de manière ambiguë, confuse, désordonnée, si aucune digression n'intervient en son sein, et si aucun des éléments nécessaires n'est omis. Elle sera brève, ensuite, si l'on ne va pas chercher les choses de trop loin, ce qu'Horace même loue chez le poète quand il dit : «Et il ne fait pas découler la guerre de Troie des deux œufs ${ }^{70}$. "

Tres aiunt esse narrationis uirtutes, ut dilucida sit, ut breuis, ut probabilis, quae licet in tota oratione lucere debent, tamen in narratione maxime requiruntur, quoniam ea est quasi sedes, et fundamentum constituendae fidei. Sed iam supra, cum de uerborum luminibus uerba faceret, docuit Cicero, quibus modus dilucida, breuis, et probabilis fiat oratio. Quare illa praecepta sunt hic repetenda. nam dilucida narratio fiet, si praeter ea, quae iam supra dicta sunt, seruetur ordo rerum, et temporum, et nihil ambigue, nihil confuse, nihil perturbate dicatur, nullaque fiat in ea digressio, et nihil eorum, quae necessaria sunt, praetermittatur. Breuis autem erit, si nimis alte non repetatur, quod Horatius etiam in poeta laudat cum ait,

Nec gemino bellum troianum orditur ab ouo.

63 Et si elle ne s'égare pas loin de son propos, que les faits sont exposés avec simplicité, sans passer par des circonlocutions. En effet, quoique la brièveté ne soit guère louée 
dans les autres parties, puisque l'éloquence doit s'exprimer avec abondance, en revanche elle est très fréquemment louée dans le cas de la narration, mais on entend par cette brièveté, celle qui écarte seulement le superflu, et non celle qui omet le nécessaire. Car, comme nous l'apprend Quintilien, la brièveté «ne consiste pas à dire moins qu'il ne faut, mais à ne pas dire plus ${ }^{71}$ ». Dans une narration, « il vaut mieux qu'il $\mathrm{y}$ ait excès en plus plutôt qu'en moins; car le superflu dégage de l'ennui, mais la suppression du nécessaire n'est pas sans risque $^{72}$ ». Aussi voyons-nous que de nombreuses narrations de Cicéron sont raisonnablement longues, comme dans les plaidoyers Pour Roscius d'Amérie, Pour Quinctius, Pour Milon, parce qu'il était nécessaire, dans ces procès, de bien informer les juges des faits de la cause, puisque, à l'évidence, ils avaient sur les faits un point de vue différent de celui de Cicéron dans sa narration. Aphtonius compte quatre vertus de la narration: la clarté, la brièveté, la vraisemblance, la correction de la langue ${ }^{73}$. Mais devant toutes les autres, c'est la vraisemblance qui est la plus nécessaire. Car si la narration n'est pas vraisemblable, il n'y aura aucun fondement sur lequel construire la confiance, et la confirmation perdra toute efficacité. C'est pourquoi Cicéron enseigne avec beaucoup de soin comment rendre la narration vraisemblable.

Et, si non aberretur a proposito, simpliciterque res exponantur, non per uerborum circuitionem. quamuis enim non semper in aliis partibus breuitas laudetur, quoniam eloquentia copiose loqui debet, tamen saepissime in narratione laudatur, sed ea breuitas intelligitur, quae superuacua tantum resecat, non quae omittit necessaria. nam in eo ponenda est breuitas, ut docet Quintilianus, non ut minus, sed ne plus dicatur, quam oporteat. Satius est enim aliquid narratione superesse, quam deesse, nam superuacua cum taedio dicuntur, necessaria cum periculo subtrahuntur. Itaque videmus multas Ciceronis narrationes esse perquam sane longas, ut pro Roscio. Am. pro Quintio, pro Milone, quoniam opus erat in eis iudiciis bene causam informare, cum aliter quam Cicero narret, ipsi iudices sentire uiderentur. Aphtonius quatuor narrationis uirtutes numerat, perspicuitatem, breuitatem, probabilitatem, sermonis proprietatem. Sed praeter caeteras omnes, probabilitas est maxime necessaria. nam, nisi uerisimilis narratio sit, nullum erit fundamentum constituendae fidei, et omnis uis confirmationis interibit. quare diligentius etiam Cicero docet, quibus modis probabilis narratio fiat.

\section{Texte de Majoragius recopié par Caussin}

[Voici la suite du texte de Majoragius, éd. citée, p. 150-155. Caussin le plagie dans son chapitre XVI, intitulé Narrationis probabilitas, ex quindecim rebus petita ( $\mathrm{La}$ vraisemblance de la narration, tirée de quinze éléments), p. 223a-224b, et dans son chapitre XVII, intitulé Quarta uirtus narrationis suauitas, in decem partes diuisa ( $\mathrm{L} a$ quatrième vertu de la narration est l'agrément, divisé en dix parties), p. 224b-225b. Les seules différences entre les deux versions sont que Caussin écourte ou supprime certains exemples de Cicéron donnés par Majoragius.]

\section{[La vraisemblance]}

" [La narration] sera vraisemblable, si les choses racontées ne sont pas en contradiction avec les personnes, avec les circonstances de temps et de lieu; si chaque fait, chaque effet reçoit son explication; si ce qu'on dit paraît établi par un témoignage appuyé sur l'opinion générale ou sur quelque autorité, conforme aux lois, aux mœurs, à la religion; si le narrateur donne de lui l'idée 
d'un homme probe, de vieille souche, doué d'une bonne mémoire, qui parle franc et auquel sa vie sert de garant ${ }^{74} »$.

Probabilis autem erit, si personis, si temporibus, si locis ea, quae narrabuntur, consentient, si cuiusque facti, et euenti causa ponetur, si testata dici uidebuntur, si cum hominum opinione, auctoritate, si cum lege, cum more, cum religione coniuncta, si probitas narrantis significabitur, si antiquitas, si memoria, si orationis ueritas, et uitae fides.

Il expose quinze manières de rendre la narration vraisemblable ${ }^{75}$.

Quindecim modis narrationem fieri probabilem ostendit,

En premier lieu, en prêtant attention aux personnes, pour lesquelles sont pris en compte le nom, la nature, le mode de vie, la fortune, la disposition morale, les affects, les goûts, les décisions, les actions, les événements inopinés, les propos.

primo, a personis, in quibus consideratur nomen, natura, uictus, fortuna, habitus, affectio, studia, consilia, facta, casus, orationes.

67 Le nom, par exemple, Publius Clodius, Annius Milon ${ }^{76}$; en effet, dans la narration on donne souvent des indications sur le nom, comme dans le Pour Roscius d'Amérie: "Car ces deux Titus Roscius, dont l'un a pour surnom Capito et l'autre, ici présent, se fait appeler Magnus ${ }^{77}$ ", et, un peu plus loin, "Une fois Sex. Roscius occis, le premier à en faire l'annonce à Amérie est un certain Mallius Glaucia, homme de peu, un affranchi, client et familier de notre T. Roscius ${ }^{78}$ ». Du reste les noms propres sont nécessaires, afin que l'on comprenne qui sont les personnes dont nous représentons les paroles.
Nomen, ut P. Clodius, Annius Milo. nam in narratione saepe nomen explicatur, pro Roscio Am. Nam duo isti sunt, T. Roscii, quorum alteri Capitoni cognomen est; iste, qui adest, Magnus uocatur ${ }^{79}$, et paulo post, Occiso Sex. Roscio primus Ameriam nunciat Mallius Glaucia quidam, homo tenuis, libertinus, cliens et familiaris istius T. Roscii. Sunt autem in narrationibus necessaria nomina propria, ut intelligatur, qui sint illi, de quibus uerba facimus.

Pour la nature, on examine si l'intéressé est craintif ou audacieux, prodigue, avare ou libéral, d'une santé robuste ou fragile, et ainsi de suite, comme Cicéron à propos de Publius Clodius: "Quand cet individu déterminé à tous les crimes vit un homme intrépide, son pire ennemi, pleinement assuré du consulat ${ }^{80} \ldots$ ». Dans le Pour Roscius d'Amérie: "En hommes d'une antique vertu, qui se représentaient les autres à la mesure de ce qu'ils étaient eux-mêmes ${ }^{81}$ ». Souvent, en effet, Cicéron montre que la nature de ceux qu'il défend est excellente, et que celle de ses adversaires est très mauvaise, à moins que d'aventure ses adversaires ne soient ses amis, comme le sont Caton $^{82}$ et Sulpicius dans le Pour Muréna: il se montre en effet plus mesuré à leur égard ${ }^{83}$.

Natura consideratur, ut timidus, an audax, an fortis, prodigus, an auarus, an liberalis, robustus an infirma ualetudine, atque ita de reliquis, ut Cicero de P. Clodio, Vbi uidit homo ad omne facinus paratissimus, fortissimum uirum, inimicissimum suum, certissimum consulem. Pro Roscio Am. Homines antiqui, qui ex sua natura caeteros fingerent. semper autem Cicero naturam eorum quos defendit, optimam esse, adversariorum pessimam ostendit, nisi forte aduersarii sint amici, ut pro L. Murena, Cato et Sulpicius, tunc enim modestius cum eis agit.

Le mode de vie est également observé, comme dans le Pour Roscius d'Amérie : «Et alors que le fils Roscius ne quittait pas les propriétés et que, pour se conformer à la volonté de son père, il s'était voué aux affaires familiales et vivait la vie d'un paysan ${ }^{84} \ldots$ ".. Le Pour Quinctius montre que Naevius a toujours mené une vie bouffonne et qu'il n'a pas appris les obligations d'un associé ${ }^{85}$. Le Pour Caelius montre que, dans sa jeunesse, il a fréquenté les meilleurs hommes : "Tant que M. Caelius fut dans la fleur de sa jeunesse, 
on ne le vit jamais avec d'autres qu'avec son père, avec moi ou dans la respectable maison de M. Crassus, où il était formé aux disciplines les plus honorables ${ }^{86}$ ».

Victus etiam spectatur, ut pro Roscio Am. Cum hic filius assiduus in praediis esset, cumque se uoluntate patris rei familiari, uitaeque rusticae dedisset; Pro P. Quintio docet Sex. Neuium semper scurrilem uitam egisse, neque iura societatis didicisse. Pro M. Caelio docet eum in adolescentia cum optimis uiris uixisse. Nemo hunc M. Caelium in illo aetatis flore uidit, nisi aut cum patre, aut mecum, aut in M. Crassi castissima domo, cum artibus honestissimis erudiretur.

Pour la fortune, on observe la noblesse, la richesse, et ce qui leur est opposé ; comme dans le Pour Roscius d'Amérie : "Sextus Roscius, père de mon client, était un citoyen du municipe d'Amérie qui, d'abord par sa naissance, sa noblesse et sa fortune, était de loin le premier personnage parmi ses concitoyens, mais aussi de la région, et qui, ensuite, jouissait de crédit et de liens d'hospitalité avec les hommes de la plus haute noblesse ${ }^{87} »$.

In fortuna spectatur nobilitas, et diuitiae, atque his contraria, ut pro Roscio Am. Sex. Roscius pater huiusce, municeps Amerinus fuit, cum genere, et nobilitate, et pecunia non modo sui municipii, uerum etiam eius uicinitatis facile primus, tum gratia atque hospitiis florens hominum nobilissimorum.

71 La disposition morale est acquise à la suite d'une longue habitude ; en effet, celui qui s'adonne longtemps à telle ou telle pratique contracte une disposition morale, dont ensuite il ne peut se défaire aussi facilement ${ }^{88}$. Il existe de bonnes et de mauvaises dispositions morales. On trouve un exemple de mauvaise disposition morale dans le Pour Quinctius (il est question de Sextus Naevius) : "C'est un grand changement de milieu; mais le caractère de Naevius ne change pas. Lui qui, dès sa prime jeunesse, s'était habitué à gagner de l'argent sans rien débourser, ne pouvait pas se contenter d'un gain médiocre, lorsqu'il eut apporté à la société je ne sais quel capital ${ }^{89} »$. Et un exemple de bonne disposition morale dans le Pour Roscius d'Amérie : "Ce père avait été, de tout temps, un fervent partisan de la noblesse, et particulièrement dans la tempête politique récente, quand la survie et la dignité de tous les nobles était en grand danger, plus que tout autre dans sa région, il s'est fait, par son activité, son zèle, son autorité, le défenseur de cette cause et de son parti ${ }^{90} »$.

Habitus longa consuetudine acquiritur; nam qui longo tempore se in aliqua re exercet, habitum contrahit, quem non ita facile deinde potest exuere. Est autem et malus et bonus habitus. Malus, ut pro P. Quinctio, de Sexto Naeuio, Fit magna mutatio loci, non ingenii. nam qui ab adolescentulo quaestum sibi instituisset, sine impendio, postea quam nescio quid impendit, et in commune contulit, mediocri quaestu contentus esse non poterat. Bonus, ut pro Roscio Am. Hic cum omni tempore nobilitatis fautor fuisset, tum hoc tumultu proximo, cum omnium nobilium dignitas et salus in discrimen veniret, praeter caeteros in ea uicinitate, eam partem causamque opera, studio, auctoritate defendit.

72 L'affect diffère de la disposition morale, parce que la disposition morale est plus durable, alors qu'un affect change aisément, comme la joie, l'espoir, le chagrin, la peur. Ainsi, dans le Pour Ligarius: "À cette nouvelle, les uns, emportés par une passion irréfléchie, les autres aveuglés par la crainte, cherchaient un chef d'abord pour les sauver, ensuite aussi pour diriger leur ardeur ${ }^{91}$ ", et, un peu après : « et lui, de toute la force de son ambition, se saisit de l'impérium ${ }^{92}{ }^{2}$.

Affectio differt ab habitu, quia habitus est diuturnior, affectio facile mutatur, ut laetitia, spes, moeror, timor, Cicero pro Q. Ligario, Quo audito, partim cupiditate inconsiderata, partim caeco quodam timore, primo salutis causa, post etiam studii sui, quaerebant aliquem ducem. paulo post, Atque ille non mediocri cupiditate arripuit imperium. 
73 Le goût est, chez une personne, le zèle fervent de son esprit à faire quelque chose, comme dans le Pour le poète Archias: "Aussitôt qu'Archias fut sorti de l'enfance et qu'après les disciplines qui préparent d'ordinaire les enfants à être des hommes cultivés, il se fut adonné à l'art d'écrire ${ }^{93} . . .1$.

Studium est uehemens animi applicatio ad aliquid agendum, quod in persona consideratur, ut pro Archia Poeta, Nam, ut primum ex pueris excessit Archias, atque ab iis artibus, quibus aetas puerilis ad humanitatem informari solet, se ad scribendi studium contulit.

74 Les décisions sont souvent développées dans les narrations, comme dans le Pour Roscius d'Amérie: «Ils conçurent le projet, d'une parfaite audace scélérate, de porter plainte contre mon client pour parricide ${ }^{94}$ ". Dans le Pour Milon : "visant moins à atteindre un degré dans la série des dignités, ce qui est l'ambition de tous les autres, qu'à éviter d'avoir pour collègue un homme de haute valeur morale ${ }^{95} \ldots$ ".

Consilia saepe explicantur in narrationibus, ut pro Rosc. Am. Consilium ceperunt plenum sceleris et audaciae, ut nomen huius de parricidio deferrent. Pro Milone, Qui non honoris gradum spectaret, ut caeteri, sed et L. Paulum collegam effugere uellet, singulari uirtute ciuem, et annum integrum ad dilacerandam rem publicam ${ }^{96}$ quaereret.

75 Quant aux actions, elles sont très souvent narrées ${ }^{97}$, comme dans le Pour Milon : «Il se désista tout à coup cette année-là qui était la sienne et se réserva pour l'année suivante $^{98}$ » et, dans le même discours, «La veille, lui-même quitta Rome à l'improviste ${ }^{99}$ ".

Facta uero saepissime narrantur; ut pro Milone, Subito reliquit annum suum, seque in annum proximum transtulit. Item, Roma subito ipse profectus pridie est.

L'événement inopiné est celui qui arrive sans avoir été espéré ou prévu, comme dans le Pour Ligarius: «La guerre éclata subitement: les gens d'Afrique apprirent qu'on se battait avant de savoir qu'on s'y préparait ${ }^{100} »$.

Casus est, qui praeter spem atque opinionem accidit, ut pro Q. Ligario, Bellum subito exarsit, quod, qui erant in Africa ante audierunt geri, quam parari.

77 Les propos rendent souvent la narration plus vraisemblable, comme dans le Pour Milon: « Il déclara ouvertement qu'il fallait tuer Milon ${ }^{101}$ ", et au même endroit, « en effet il répétait en public qu'on ne pouvait arracher le consulat à Milon, mais qu'on pouvait lui arracher la vie ${ }^{102} »$.

Orationes multo probabiliorem saepe narrationem faciunt, ut pro Milone, Palam agere coepit, et aperte dicere occidendum Milonem. Item, Etenim palam dictitabat consulatum Miloni eripi non posse, uitam posse.

Tous ces éléments touchant aux personnes doivent être pris en considération.

Haec omnia sunt in personis consideranda.

En deuxième lieu, on rend la narration vraisemblable en mentionnant les circonstances temporelles, comme dans le Pour Milon, où Cicéron prouve que Clodius a tendu des pièges à Milon, parce que Milon recherchait le consulat au moment où Clodius voulait la préture ${ }^{103}$. Dans le Pour Ligarius: "Q. Ligarius, à un moment où rien ne laissait pressentir une guerre, partit pour l'Afrique comme légat de C. Considius ${ }^{104} »$. Le Pour Caelius montre par une circonstance temporelle que Caelius n'était pas un ami de Catilina ${ }^{105}$.

Secundo, fit narratio probabilis a temporibus, ut pro Milone probat insidias a Clodio Miloni factas, quoniam eodem tempore Milo consulatum petebat quo Clodius praeturam. pro Q. Ligar. Q. Ligarius, cum esset adhuc nulla belli suspicio, legatus in Africam cum proconsule C. Considio profectus est. pro M. Caelio docet a tempore Caelium Catilinae familiarem non fuisse. 
En troisième lieu, on rend la narration vraisemblable en mentionnant le lieu, comme dans le Pour Milon: "pour organiser, devant un de ses domaines, un attentat contre Milon $^{106}$ ». Souvent même, les narrations commencent par le lieu, comme dans la troisième Verrine, «Lampsaque, dans la région de l'Hellespont, juges... ${ }^{107}$ ». On articule parfois ensemble le lieu et le temps, comme dans le Pour Roscius d'Amérie: "Sextus Roscius est tué, près des bains de Pallacine, de retour d'un souper ${ }^{108} »$. Dans le Pour Milon, «La rencontre avec Clodius eut lieu devant un domaine de celui-ci, à la onzième heure, ou peu s'en faut ${ }^{109} »$.

Tertio a loco fit probabilis narratio, ut pro Milone, ut ante fundum suum insidias Miloni collocaret. Saepe etiam a loco narrationes incipiunt, ut tertia in Verrem, Oppidum in Hellesponto Lampsacum, iudices. Interdum locus, et tempus una copulantur, ut pro Roscio Am. Occiditur ad balneas palatinas rediens a coena Sex. Roscius. Pro Milone, Fit obuiam Clodio ante fundum eius hora fere undecima, aut non multo secus.

81 En quatrième lieu, si la cause d'une action ou d'un événement est exposée, la narration sera vraisemblable, car l'explication des causes inspire la confiance, par exemple: pourquoi Clodius a-t-il tendu un piège à Milon? parce qu'« il était clair pour lui que sa prêture serait infirme et paralysée avec un consul tel que Milon ${ }^{110}$ » Pourquoi a-t-il convoqué des esclaves? Pourquoi a-t-il enrôlé les pires des citoyens ? Pourquoi était-il "sans rien qui le gêne, à cheval, sans voiture, sans bagages encombrants, n'ayant pas avec lui les esclaves grecs qui auparavant étaient ses compagnons ordinaires ${ }^{111}$ "? Pour tendre des pièges. «Pourquoi donc a-t-il été vaincu ? C'est que le voyageur n'est pas toujours tué par le brigand; parfois même c'est le brigand qui est tué par le voyageur. C'est qu'en attaquant, bien préparé, des gens pris au dépourvu, il n'en était pas moins une femme qui se heurte à des hommes ${ }^{112}$. »

\begin{abstract}
Quarto, si cuiusque facti, et euenti causa ponetur, erit probabilis narratio. causarum enim explicatio fidem facit, ut, Cur Clodius insidias Miloni fecit? quia occurrebat ei mancam, ac debilem praeturam suam futuram consule Milone. Cur seruos Clodius congregauit? Delectum perditissimorum ciuium habuit ${ }^{113}$ ? expeditus in equo, nulla raeda ${ }^{114}$, nullis graecis comitibus, ut antea ${ }^{115}$ solebat, nullis impedimentis Roma profectus est? nempe ut insidias strueret. Cur igitur uictus est? quia non semper uiator a latrone, nonnunquam etiam latro a uiatore occiditur, quia quanquam paratus in imparatos Clodius; tamen mulier inciderat in uiros.
\end{abstract}

82 En cinquième lieu, si ce qu'on dit paraît établi par un témoignage, comme dans le Pour Milon: «Bien plus, M. Favonius, cet homme de cœur, lui demandant ce qu'il pouvait attendre de ses fureurs du vivant de Milon, il répondit que dans trois jours, quatre au plus, Milon serait mort. Ces paroles, Favonius les rapporta à M. Caton ici présent ${ }^{116} »$.

Quinto, si testata dici uidebuntur, ut pro Milone, Quin etiam Fauonio fortissimo uiro quaerenti ex eo, qua spe fureret, Milone uiuo, respondit triduo illum, ad summum quatriduo esse periturum, quam uocem eius ad hunc M. Catonem statim Fauonius detulit.

83 En sixième lieu, si la narration s'appuie sur l'opinion commune, comme dans le Pour Roscius d'Amérie, à propos de la vie à la campagne : «C'est le mode de vie le plus éloigné de la convoitise et le plus proche du sens du devoir ${ }^{117}$ ». Et dans le Pour Milon: «ces esclaves de Milon se conduisirent alors comme chacun aurait voulu que ses esclaves se conduisissent en pareille circonstance ${ }^{118} »$.

Sexto, si cum hominum opinione, ut pro Roscio Am. de uita rustica, Quae uita maxime disiuncta a cupiditate, et cum officio coniuncta. Pro Milone, Fecerunt serui Milonis, quod suos quisque seruos in tali re facere uoluisset.

84 En septième lieu, si la narration s'appuie sur l'autorité, comme dans le Pour Roscius d'Amérie: «Il pensait être de son devoir de se battre pour l'honorabilité de ceux grâce 
auxquels il comptait comme le plus honorable parmi les siens ${ }^{119}$ ». Car l'autorité a une très grande efficacité pour inspirer la confiance, ou bien envers celui qui prononce le discours, ou bien envers celui qui fait l'objet du discours. En effet, on fait plus facilement crédit aux hommes dotés d'une grande autorité, parce qu'on ne les soupçonne nullement de mensonge, et ce qui est dit à propos d'un homme de grande autorité, on l'approuve facilement: par exemple, si l'on raconte que Caton est l'ami de la patrie, qu'il est étranger à la cupidité, qu'il est courageux, et ferme dans ses affaires $^{120}$. L'autorité peut même être rapportée à la responsabilité politique, comme dans les Verrines, où Cicéron raconte les nombreux actes scandaleux que Verrès perpétrait, au nom de l'autorité de la charge politique qu'il exerçait ${ }^{121}$.

Septimo, si cum auctoritate coniuncta, ut pro Roscio Am. Etenim rectum putabat pro eorum honestate se pugnare, propter quos ipse honestissimus inter suos numerabatur. Auctoritas enim maximam uim habet ad fidem faciendam, uel in eo qui dicit, uel in eo de quo dicitur. Nam auctoritate magna praeditis hominibus facilius creditur, quia non est in eis ulla mendacii suspicio, et quae dicuntur de uiro magnae auctoritatis, facile probantur, ut si quis narret Catonem esse amantem patriae, alienum ab auaritia, fortem, et constantem in negotiis. Potest etiam auctoritas ad imperium referri, ut in Verrinis Cicero multa narrat, quae Verres pro auctoritate imperii, quod gerebat, flagitiose perpetrarat.

En huitième lieu, si elle s'appuie sur la loi, comme dans le Pour Milon, où Cicéron prouve qu'il est permis à chacun de repousser la force par la force selon la loi de la nature. « Ce n'est donc pas, dit-il, Juges, une loi écrite mais une loi naturelle que nous ne devons ni à l'enseignement, ni à la tradition, ni à la lecture mais uniquement à la nature. C'est de là que nous l'avons tirée, que nous l'avons puisée, que nous l'avons extraite, cette loi non pas apprise mais innée, à laquelle nous n'avons pas été formés, mais dont nous sommes pénétrés, etc. ${ }^{122}$ ». Il prouve que ce même acte est permis par les lois des Douze Tables ${ }^{123}$.

Octauo, si cum lege, ut pro Milone Cicero lege naturae probat unicuique licere uim repellere. Est enim ${ }^{124}$, inquit, haec Iudices non scripta, sed nata lex, quam non didicimus, accepimus, legimus, uerum ex natura ipsa arripuimus, hausimus, expressimus, ad quam non docti, sed facti, non instituti, sed imbuti sumus, et quae sequuntur. Probat hoc idem etiam a legibus duodecim tabularum esse concessum.

En neuvième lieu, si elle est associée à la coutume et à l'habitude. Par exemple, dans le même discours:»S'il est vrai au contraire que la raison a prescrit aux hommes civilisés, la nécessité aux barbares, les conventions sociales aux peuples organisés, la nécessité aux barbares, les conventions sociales aux peuples organisés et l'instinct aux bêtes sauvages, de repousser dans tous les cas, par tous les moyens, la violence qui menace leur corps, leur tête, leur vie, etc. ${ }^{125}$ ».

Nono, si cum more et consuetudine, ut in eadem oratione. Sin hoc, et ratio doctis, et necessitas barbaris, et mos gentibus, et feris natura ipse praescripsit, ut omnem semper uim, quacumque ope possent, a corpore, a capite, a uita sua propulsarent, et caetera.

En dixième lieu, si elle s'appuie sur la religion. Par exemple, au même endroit : « Milon avait à faire à date fixe un voyage officiel et obligatoire : il devait se rendre à Lanuvium pour la désignation d'un flamine, car Milon était dictateur à Lanuvium ${ }^{126}$ ".

Decimo, si cum religione coniuncta, ut ibidem., Iter solemne, legitimum, necessarium Miloni esse Lanuuium ad flaminem prodendum, quod erat dictator Lanuuii Milo.

En onzième lieu, si le narrateur donne de lui une image d'honnêteté. En effet, les honnêtes hommes ont coutume de croire en elle ${ }^{127}$. C'est la raison pour laquelle Aristote compte au nombre des preuves techniques les mœurs de l'orateur même, telles qu'elles ressortent de son discours ${ }^{128}$. De même, souvent les mœurs qui ressortent de l'affaire, si 
elles sont exprimées, sont également efficaces ${ }^{129}$, comme dans le Pour Milon : " Je ne dis rien de l'avantage qui en résulte pour l'État, non plus que pour vous-mêmes, non plus que pour les gens de bien. J'admets que cela ne serve en rien la cause de Milon, dont le destin est de n'avoir pu assurer son propre salut sans assurer en même temps le salut de l'État et le vôtre ${ }^{130} »$.

Undecimo, si probitas narrantis significabitur. probis enim uiris facile credi solet. Ideo Aristoteles inter probationes artificiosas, mores etiam dicentis oratione expressos ponit ${ }^{131}$. Idem ualent saepe mores etiam ipsius rei si exprimantur, ut pro Milone. Nihil dico, quid res publica consecuta sit, nihil, quid uos, nihil quid omnes boni, nihil sane id prosit Miloni, qui hoc fato natus est, ut ne se quidem seruare potuerit, quin una rem publicam uosque seruaret.

89 En douzième lieu, si on y trouve un air antique, c'est-à-dire une gravité dans le discours, qui porte avec elle une sorte d'antiquité et de respect, comme dans le Pour Milon: «visant moins à atteindre un degré dans la série des dignités, ce qui est l'ambition de tous les autres, qu'à éviter d'avoir pour collègue un homme de haute valeur morale, L. Paulus ${ }^{132}$, etc. ".

Duodecimo, si antiquitas, hoc est orationis grauitas, quae antiquitatem quandam et uenerationem prae se ferat, ut pro Milone, Qui non honoris gradum spectaret, ut caeteri; sed et L. Paulum collegam effugere uellet singulari uirtute ciuem, et caetera.

90 En treizième lieu, si l'orateur montre sa bonne mémoire : en effet, ce qui est raconté de mémoire et avec netteté semble vrai, alors que si quelqu'un s'interrompt, tient un propos hésitant, et se contredit, il semble dire des mensonges: comme le dit le proverbe, au menteur il faut une bonne mémoire ${ }^{133}$.

Tertiodecimo, si memoria dicentis significabitur. nam ea, quae prompte, et memoriter narrantur, uera esse uidentur; cum autem quis haeret in dicendo ac uacillat, neque sibi constat, ficta loqui uidetur, ideo prouerbio dicitur. Mendacem esse memorem oportere.

91 En quatorzième lieu, si la vérité du discours est manifeste, c'est-à-dire si l'orateur a eu coutume de longue date de dire des choses vraies; en effet, il est vraisemblable que celui qui par le passé a toujours toujours été sincère, raconte encore la vérité à présent ; alors que celui qui a été menteur en vient à ne pas être cru quand il dit la vérité.

Quartodecimo, Si orationis ueritas, hoc est, si antea solitus est uera dicere. probabile est enim eum, qui semper antea ueridicus fuit, etiam nunc uera narrare; mendax autem id assequitur, ut neque cum uera dicit, ei credatur.

Enfin, la confiance qu'on accorde à la vie de l'orateur rend son discours très vraisemblable; car la vie qu'il a menée auparavant est un puissant témoignage : en effet, un homme criminel et malhonnête n'inspire aucune confiance, alors qu'on donne facilement son crédit à un homme honnête : c'est pourquoi l'on dit que l'orateur doit être un homme de bien ${ }^{134}$.

Vltimo, uitae fides maxime probabilem efficit orationem. uita enim anteacta firmum quoddam testimonium est. scelestus enim et improbus nullam fidem habet, probo uero homini facile creditur ; idcirco dicunt oratorem bonum uirum esse opportere.

\section{[L'agrément]}

"On trouvera de l'agrément aux narrations qui présentent des passages qui étonnent, qui suscitent l'attente, des dénouements inattendus, par endroits des mouvements pathétiques, des dialogues, de la douleur, de la colère, de la crainte, de l'allégresse, des désirs passionnés. Mais voyons le reste ${ }^{135}$. » 
Suauis autem narratio est, quae habet admirationes, expectationes, exitus inopinatos, interpositos motus animorum, colloquia personarum, dolores, iracundias, metus, laetitias, cupiditates. Sed iam ad reliqua pergamus.

En premier lieu, l'étonnement, qui est suscité quand nous racontons des choses grandes, ou nouvelles et inouïes. Des choses grandes, par exemple si quelqu'un raconte qu'un père a été défendu et protégé par Scipion adolescent, alors qu'Hannibal le pressait de se battre. De même, Cicéron montre la grandeur d'un exploit de César: adolescent, presque encore un enfant, il a rassemblé une armée de vétérans, il a prodigué son patrimoine et s'est opposé à la fureur de Marc Antoine ${ }^{136}$; de ce même exploit, Cicéron montre qu'il est nouveau et inouï. « Nombreux sont les faits dont je me souviens, que j'ai entendu conter, ou que j'ai lus; mais, dans l'histoire de tous les siècles, je ne connais rien de pareil ${ }^{137}$ ». De même, dans le Pour Cluentius: «Forfait incroyable de cette femme, et, sauf ce cas unique, inouï dans le monde ${ }^{138}$ !»

primo admirationem, quae tum excitatur, cum aut magna, aut noua, et inaudita dicimus. Magna, ut si quis narraret a Scipione adolescente defensum fuisse patrem, ac protectum, cum Annibal eum urgeret in proelio. Ita Cicero magnum ostendit fuisse factum Caesaris Octauiani, quod adolescens, ac pene puer, exercitum ueteranorum compararit, patrimonium effuderit, et M. Antonii furori obstiterit. Quin eiusdem factum ostendit esse nouum, et inauditum, Multa, inquit, memini, multa audiui, multa legi, nihil ex omnium saeculorum memoria tale cognoui. Ita pro A. Cluentio, O mulieris scelus incredibile; et praeter hanc unam in omni uita inauditum.

En deuxième lieu, l'attente est très agréable, quand les auditeurs se demandent si la chose sera menée à bien, comme dans le Pour Cluentius. "L'attente de tous était à son comble : quel vote allait être celui de ces juges vénaux et sans caractère ${ }^{139}$ ?» Et : «Cette union était des plus considérées, des mieux accordées quand soudain se manifesta la passion impie d'une femme sinistre, passion dont le déshonneur et même le crime nouèrent les liens ${ }^{140} »$. Dans ce but, on fait beaucoup de détours en paroles et de préparations dans le discours, afin de susciter une plus grande attente : c'est ce que fait très souvent Cicéron dans ses Verrines ${ }^{141}$. Dans les comédies et les tragédies, l'attente des événements à venir charme beaucoup.

Secundo, expectationes concitatae multum delectant, cum dubitant auditores quo res si euasura, ut pro A. Cluentio, Summa omnium expectatio, quidnam sententiae ferrent nummarii Iudices. Pro eodem, Cum essent hae nuptiae plenae dignitatis, plenae concordiae, repente est exorta mulieris importunae nefaria libido, non solum cum dedecore, uerum etiam scelere coniuncta. Hac de causa, multi fiunt circuitus uerborum et praeparationes in dicendo, ut maior expectatio concitetur, quod in Verrem frequentissime Cicero facit, in comoediis, et tragoediis expectationes rerum futurarum concitatae magnopere delectant.

En troisième lieu, un dénouement imprévu, quand il est heureux, apporte un très grand plaisir, ce que Cicéron formule ainsi : «Au contraire, souvent, il y a dans la destinée variée et mouvementée d'un homme éminent ${ }^{142}$ de quoi provoquer étonnement et confiante attente, joie et peine, espoir et crainte ; et si elle s'achève par une belle fin, l'esprit du lecteur éprouve la satisfaction la plus vive et la plus complète ${ }^{143} »$ : tels sont tous les dénouements des comédies, c'est-à-dire imprévus et heureux.

Tertio exitus inopinati, quando felices apparent, summam afferunt iucunditatem, quod ita Cicero affirmat, At uiri saepe excellentes, ancipites, uariique casus habent admirationem, expectationem, laetitiam, molestiam, spem, timorem : si uero exitu notabili concluduntur, expletur animus iucundissimae lectionis uoluptate. Tales sunt omnes comoediarum exitus, hoc est, inopinati, et felices. 
En quatrième lieu, la narration acquiert de l'agrément quand des mouvements de l'âme font irruption. En effet, comme le dit Aristote, dans tout mouvement de l'âme il y a un certain plaisir ${ }^{144}$. Ainsi, Cicéron, dans son Pour Cluentius, parle de Sassia ${ }^{145}$, la mère de Cluentius : «Puis elle en vint à brûler d'une telle folie, à s'abandonner à des désirs si enflammés qu'il n'y eut ni honneur, ni pudeur, ni piété, ni tache infligée à sa famille, ni opinion publique, ni chagrin d'un fils, ni douleur d'une fille qui purent la détourner de sa passion. Elle séduisit un cœur juvénile que la réflexion et la raison n'avaient pas encore affermi ${ }^{146}$, etc. »

Quarto, suauis fiet narratio, si motus animi interponantur. Nam, ut ait Aristoteles, in omni animi motu inest quaedam iucunditas. Cicero pro A. Cluentio de Sassia Cluentii matre; Deinde ita flagrare coepit amentia, sic inflammata ferri libidine, ut eam non pudor, non pudicitia, non pietas, non macula familiae, non hominum fama, non filii dolor, non filiae maeror, a cupiditate reuocaret, animum adolescentis nondum consilio ac ratione firmatum pellexit, et reliqua.

En cinquième lieu, il est agréable de lire au sein de la narration des discussions entre les personnages, comme dans la troisième Verrine. «Pourquoi, dit-il alors, pourquoi, je te prie, Philodamus, ne fais-tu pas convier ta fille à venir au milieu de nous, dans cette salle? ? et, un peu plus loin: "Alors, pour répondre quelque chose, il déclara qu'il n'était pas dans les coutumes des Grecs que les femmes se missent à table à un repas d'hommes. Mais alors, d'une autre partie de la salle, un autre convive de s'écrier : "Cela vraiment n'est pas supportable ; que l'on convie cette femme à notre repas" ${ }^{147}$ ! ", etc.

Quinto colloquia personarum in narratione delectant, ut tertia in Verrem, Quaeso, inquit, Philodame, cur ad nos filiam tuam ${ }^{148}$ non intro uocari iubes? et paulo post, Tum ille, ut aliquid responderet, negauit moris esse graecorum, ut in conuiuio uirorum accumberent mulieres. hic tum alias ex alia parte, enimuero ferendum hoc non est, uocetur mulier, et quae sequuntur.

100 En sixième lieu, l'expression de la douleur charme, car il y a du plaisir jusque dans la douleur, comme dans ce passage du Pour Roscius d'Amérie: "Ces procédés parurent d'une telle indignité aux habitants d'Amérie que, dans la ville entière, ce n'étaient que pleurs et gémissements ${ }^{149}$ ». Et dans le Pour Cluentius : «C'est dans les bras, dans le sein de ce frère très aimant qu'elle se consumait de chagrin et de larmes ${ }^{150}$ ».

Sexto dolores expressi delectant, inest enim quaedam etiam in dolore iucunditas, ut pro Roscio Am. Quod Amerinis usque eo uisum est indignum, ut urbe tota fletus, gemitusq. fierent. Pro A.Cluentio, in huius amantissimi sui fratris manibus et gremio, moerore et lachrymis consenescebat.

101 En septième lieu, les colères provoquent le plaisir. Homère en effet chante ainsi au sujet de la colère, comme le cite Aristote ${ }^{151}$ : «elle est beaucoup plus douce que le miel répandu goutte à goutte, quand elle croît dans des poitrines humaines ${ }^{152}$ ». Ainsi, Cicéron dans son Pour Roscius d'Amérie : «Il n'était personne qui n'eût préféré tout oser plutôt que de voir T. Roscius promener sa jactance de seigneur et maître dans les domaines de Sex. Roscius, le meilleur et le plus honnête des hommes ${ }^{153}$ ».

Septimo, iracundiae mouent delectationem. nam Homerus ita de ira cecinit, ut citat

Aristoteles.

Dulcior effuso quae melle in pectore gliscit.

Cicero pro Roscio Am. Nemo erat, qui non ardere omnia mallet, quam uidere in Sex. Roscii

optimi uiri, atque honestissimi bonis iactantem se ac dominantem T. Roscium.

102 En huitième lieu, l'inquiétude donne de l'agrément à la narration, comme dans le Pour Roscius d'Amérie : «Car il était saisi d'une crainte si violente qu'il aurait préféré mourir plutôt que de voir Sylla instruit de ce qui s'était passé154 ». Et dans sa troisième Verrine : 
"Dès que l'on eut annoncé ces événements au fils de Philodamus, aussitôt il se hâte, tout hors d'haleine, vers la maison, pour porter secours à la vie de son père et à l'honneur de sa sœur ${ }^{155}$ ».

Octauo, metus in narratione suauitatem afferunt, ut pro Roscio Am. Vsque adeo autem ille pertimuerat, ut mori mallet, quam de his rebus Syllam doceri. tertia in Verrem, Haec ubi filio nunciata sunt, statim exanimatus ad aedes contendit, ut et uitae patris, et pudicitiae sororis succurreret.

En neuvième lieu, la joie rend la narration agréable, comme dans le Pour Cluentius: "Mais alors cette mère si noble et si digne de gloire se mit aux yeux de tous à exulter de joie, à triompher d'allégresse ${ }^{156}$ ». Et dans la troisième Verrine : «La conversation s'engage entre eux, ils s'invitent mutuellement à boire, selon la coutume grecque ; leur hôte les encourage; ils réclament pour boire des coupes plus grandes; le festin se poursuit au milieu des conversations et d'une gaieté générale qui l'animent ${ }^{157}$ ».

Nono, laetitiae faciunt iucundam narrationem, ut pro Cluentio, Tum uero illa egregia, ac praeclara mater, palam exultare laetitia, ac triumphare gaudio coepit. tertia in Verrem, Fit sermo inter eos et inuitatio, ut graeco more biberetur, hospes hortatur, poscunt maioribus poculis, celebratur omnium sermone, laetitiaque conuiuium.

En dixième et dernier lieu, l'expression des désirs passionnés [cupiditates] charme, comme dans le Pour Roscius d'Amérie : "Voilà le dessin qu'ils ont formé ; voilà l'état de folie où ils en sont arrivés et qui les a poussés à vous livrer pour l'égorger celui que, malgré leur désir passionné, ils n'ont pas pu mettre à mort ${ }^{158}$ ». " Elle veut bien verser tout le sang de ses veines pourvu qu'elle ait vu d'abord répandre celui de son fils ${ }^{159} »$.

Decimo et ultimo, cupiditates expressae delectant, ut pro Roscio Am.

Hoc consilio, atque adeo hac amentia impulsi, quem ipsi cum cuperent, non potuerunt occidere, eum iugulandum uobis tradiderunt. Pro Cluentio, Sanguinem suum profundere omnem cupit, dum modo profusum huius ante uideat ${ }^{160}$.

\section{NOTES}

1. Voir fig. 1 et fig. 2.

2. Quand N. Caussin (1583-1651) rédige les Parallèles de l'éloquence et profane (Eloquentiae sacrae et humanae parallela libri XVI, Paris, S. Chapelet, 1619), il est professeur au collège de La Flèche ; voir C. de Rochemonteix, Un collège de Jésuites aux XVII et XVIII ${ }^{e}$ siècles. Le collège Henri IV de La Flèche, t. III, Le Mans, Leguicheux, 1889, p. 31.

3. Voir l'introduction et la traduction que nous en avons données pour Exercices de rhétorique, $\mathrm{n}^{\circ}$ 15, 2020 («Le péché par l'excès : quelques vices de style selon Nicolas Caussin »).

4. Voir P. Aubenque, La Prudence chez Aristote, Paris, Presses Universitaires de France, 1963 ; et F. Goyet, Les Audaces de la prudence. Littérature et politique aux XVI et XVII siècles, Paris, Garnier, 2009.

5. N. Caussin, Eloquentiae sacrae et humanae parallela, op. cit., p. 223a. Voir infra, note 72.

6. Cicéron, Divisions de l'art oratoire, IX, 32, éd. et trad. H. Bornecque, Paris, Les Belles Lettres, 1990, p. 15.

7. Ibid. Nous modifions la traduction de H. Bornecque en remplaçant «qui captivent » par «qui suscitent l'attente » pour traduire «quae habet expectationes». Quintilien cite ce texte : Institution 
oratoire, IV, II, 107. « Or, pour qu'on ne croie pas qu'il a fait cela sans dessein, ce qu'on ne saurait présumer d'un pareil orateur, il recommande, dans ses Partitions, de donner de la douceur à la narration, d'y ménager la surprise, l'attente, les effets imprévus, d'y introduire des dialogues, enfin toutes les passions ", éd. et trad. J. Cousin, Paris, Les Belles Lettres, 1976, t. III, p. 68 (où le titre «Partitions» renvoie aux Divisions de l'art oratoire, en latin Partitiones oratoriae, abréviation Part.). Caussin change ici de section: il s'agit chez lui du chapitre XVII, intitulé Quarta uirtus narrationis suauitas, in decem partes diuisa (La quatrième vertu de la narration est l'agrément, divisé en dix parties), p. 224b-225b.

8. Voir notamment Hélène Maurel-Indart, Du Plagiat, Paris, Presses Universitaires de France, collection "Perspectives Critiques", 1999, et Charles Coustille, "Une histoire du plagiat universitaire», Atelier Fabula, 2011, https://www.fabula.org/atelier.php? histoire_du_plagiat_universitaire.

9. Nous remercions Romain Menini de nous avoir signalé un exemplaire de l'Antiparadoxon de Majoragius (Lyon, Gryphe, 1546), qui porte sur la page de titre l'ex-libris manuscrit d'un collège jésuite daté de 1639 ; exemplaire numérisé sur Google Books: https://www.google.fr/books/ edition/M_Antonii_Majoragii_Antiparadoxon_libri/chHP6rRCFYcC?hl=fr\&gbpv=1.

10. Mais connus de Francis Goyet et de Christine Noille : nous remercions Christine Noille qui nous a aussitôt indiqué le texte de Majoragius d'après la citation qu'en faisait Caussin p. 223a.

11. Nous nous fondons notamment ici sur l'article «Marcantonio Maioragio » de la Storia della letteratura italiana de G. Tiraboschi (Milan, Società tipografica de' classici italiani, 1824 [1772-1782], t.7, p. 2207-2211), et sur celui du Dictionnaire historique et critique de P. Bayle, Rotterdam, Michel Bohm, 1720 (troisième édition), p. 1881-1883.

12. Bayle en doute : «En voici un qui s'est fait plus jeune qu'il ne l'était à son entrée aux charges publiques ", ibid., p. 1882.

13. Comme le note Tiraboschi (op. cit., p. 2208), une lettre de Bartolomeo Ricci à Nizzoli fait douter du fait que le séjour à Ferrare n'ait duré qu'un an. En effet, il affirme avoir conversé avec lui pendant trois ans : «Amo non leviter Majoragium ob ejus optima studia singularemque humanitatem, quo Ferrariae sic sum triennio usus, ut nullus usquam alio familiarius. »

14. Bayle, op. cit., p. 1883.

15. Disquisitiones in libros officiorum M. Tulli, 1544. Majoragius y répond dans ses Decisiones XXV quibus M. Tullium Ciceronem omnibus Caeli Calcagnini criminationibus liberat (1544).

16. Antiparadoxa sive suburbanarum quaestionum libri sex in quibus omnia M. T. Ciceronis paradoxa refelluntur, 1546. Pour un résumé et une analyse des enjeux de la querelle, voir C. Marras, "Antibarbarous contra Pseudophilosophers », in Traditions of Controversy, dir. M. Dascal et H.L. Chang, Philadelphia, John Benjamins, 2007, p. 165-179.

17. Voir C. Vasoli, « Un episodio della disputa cinquecentesca su Cicerone e il ciceronianesimo : Mario Nizolio e Marcantonio Maioragio ", Civitas Mundi. Studi sulla cultura del Cinquecento, Rome, Edizioni di storia e letteratura, 1996, p. 235-260.

18. "Questa è l'unica taccia che oscuri alquanto la fama di si valoroso scrittore, il quale e per eleganza e per eloquenza e per erudizione può andar del pari co' migliori del secolo XVI", "Marcantonio Maioragio ", art. cit., p. 2211.

19. Sur ce texte de Leibniz, voir C. Marras et G. Varani, «I dibattiti rinascimentali su retorica e dialettica nella 'Prefazione al Nizolio' di Leibniz », Studi Filosofici, 2004, n² 27, p. 184-216.

20. Op. cit., p. 1883.

21. M. Antonii Majoragii explanationes in tres Aristotelis libros de Arte Rhetorica, Venise, Fr. Franciscius, 1572. Nous nous référons dans notre édition à ce commentaire, qui permet d'éclaircir une allusion de Majoragius à Aristote, voir la note 141.

22. Idée de l'estude d'un honeste homme, B. M. Lyon, Ms 1514, entre 1658 et 1661, f. V vº (graphies modernisées ; le dernier auteur mentionné est Gérard Pelletier) ; nous remercions Francis Goyet 
et Judi Loach de cette précieuse référence - tous deux préparent l'édition annotée de la Novae et veterae eloquentiae de Menestrier (Lyon, s. n., 1663), à paraître chez Garnier.

23. Philippe-Louis Joly, Remarques critiques sur le Dictionnaire de Bayle, Paris, Hyppolite-Louis Guerin et Dijon, Dlle Hermil-Andrea, 1748, « Majoragius (Marc-Antoine) », p. 510.

24. Cicéron, Pour Milon, IX, 24, dans Discours, t. XVII, éd. et trad. A. Boulanger, Paris, Les Belles Lettres, 1949, p. 93. Cet exemple est également employé infra, à propos de l'air antique (antiquitas), voir n. 129. Dans son plagiat, Caussin supprime cet exemple (Parallela, op. cit., p. 223 b).

25. L'Orateur. Du meilleur genre d'orateurs, XXX, 107, texte établi et traduit par Albert Yon, Paris, les Belles Lettres, 1964, p. 37.

26. Ibid.

27. Ainsi de Pline (Lettres, 1, 20,5), ainsi de Sidoine Apollinaire : «le grand orateur, s'il s'attaque à une affaire de mince importance, n'en est que plus applaudi en montrant son vaste talent. Cicéron, qui dépasse dans ses autres plaidoiries tous les autres orateurs, se surpasse lui-même dans sa défense d'Aulus Cluentius " (Sidoine Apollinaire, lettre à Ruricius, VIII, 10, 3, dans Lettres, tome III (livres VI-IX), éd. et trad. A. Loyen, Paris, Les Belles Lettres, 1970, p. 109).

28. Quintilien, Institution oratoire, IV, II, 31, op. cit., t. III, p. 47. Nous modifions légèrement la traduction de J. Cousin qui, pour éviter la répétition de claire, traduit la seconde occurrence de lucidam par « limpide », ce qui rajoute un synonyme au texte de Quintilien alors que ce dernier ne donne que deux mots, lucidam et perspicuam, pour rendre l'idée de clarté.

29. Sur la coprésence, au XVII ${ }^{\mathrm{e}}$ siècle, de différents types de vraisemblance hérités de la tradition rhétorique et de la Poétique d'Aristote, voir les travaux d'A. Duprat, en particulier «Les trois formes de la vraisemblance au XVII ${ }^{\mathrm{e}}$ siècle", dans M. Baschera, P. Dumont, A. Duprat et D. Souiller, Vraisemblance et représentation au XVII siècle: Molière en question, Littérature comparée, $\mathrm{n}^{\circ}$ 2, 2004, p. 219-234.

30. À André Falconet, 6 septembre 1649, Correspondance complète et autres écrits de Guy Patin, éd. L. Capron, lettre 196, https://www.biusante.parisdescartes.fr/patin/.

31. Voir notamment, comme nous l'a signalé Ch. Noille, Aristote, Rhétorique III, 13, $1414 a 36$ : « La narration, en effet, n'appartient guère qu'au seul discours judiciaire. Comment peut-il y avoir dans le discours épidictique ou le discours d'assemblée une narration telle qu'on l'entend ? » (éd. et trad. P. Chiron, Paris, Flammarion, 2007).

32. Citation déformée de l'Institution oratoire de Quintilien, IV, II, 11 : «Ego autem, magnos alioqui secutus auctores, duas esse in iudiciis narrationum species existimo, alteram ipsius causae, alteram in rerum ad causam pertinentium expositione "; "Pour ma part, et en cela je suis du reste de bons auteurs, j'estime que, dans les affaires judiciaires, il y a deux espèces de narrations; l'une consiste à exposer les faits de la cause elle-même, l'autre les circonstances qui s'y rapportent » (éd. et trad. J. Cousin, op. cit., t. III, p. 41-42).

33. Voir Cicéron, Pour Milon, XXIII, 62-64.

34. Aristote, dans sa Rhétorique (III, 13, 1414b14), critique également les distinctions excessives. Il fait remonter à Théodore de Byzance, auteur de la fin $\mathrm{du} \mathrm{v}^{\mathrm{e}}$ siècle que Platon cite dans le Phèdre (266e), la distinction entre diègèsis, epidiègèsis et prodiègèsis. Martianus Capella, au ve siècle, écrit que Théodore distinguait plus précisément encore prodiègèsis, hypodiègèsis, paradiègèsis, anadiègèsis et katadiègèsis (Noces de Philologie et de Mercure, V, 552, dans Martianus Capella and the Seven Liberal Arts, vol. II, The Marriage of Philology and Mercury, éd. William Harris Stahl with E. L. Burge, New York, Columbia University Press, 1971, p. 382).

35. Caussin reprend l'Ars rhetorica de Consultus Fortunatianus (alors souvent appelé à tort Curius), II, 19, Ars rhetorica Consulti Fortunatiani, traduzione italiana e commento a cura di Lucia Calboli Montefusco, Bologna, Pàtron, 1979, p. 124-125 pour le latin et 216-217 pour la traduction. 
36. Fortunatianus: "diegesis, quae narratio est principalis» ("dieghesis (narrazione), che è la narrazione principale »).

37. Ibid. : « antidiegesis, cum adversarii adferimus narrationem converso genere, sicuti dixi " ("c'è anche l'antidieghesis (narrazione opposta), quando, come dissi, col genere scambiato riportiamo la narrazione dell'avversario »). L. Calboli Montefusco comprend adversarii comme un génitif. On pourrait également le comprendre comme un nominatif pluriel et traduire : «il y a antidiégèse quand nous apportons en adversaires notre narration sur le mode contradictoire ».

38. Ibid. : "merice diegesis, cum partes singulas narrationis inducimus" ("c’è anche la merice dieghesis (narrazione divisa), quando esponiamo singole parti della narrazione »).

39. «Seius» est le prénom romain conventionnel («Untel») qu'emploie constamment le Digeste. Nous remercions F. Goyet de cette indication.

40. Ibid. : " paradiegesis, cum aliquas res gestas causam positas inducimus, quibus iudicis animum ad id, quod causa desiderat, confirmemus" ("c'è anche la paradieghesis (narrazione accessoria), quando esponiamo alcuni fatti posti al di fuori della causa, coi quali rafforziamo l'interesse del giudice verso ciò che la causa richiede »).

41. Le verbe subintexere semble être un néologisme de Caussin (il l'utilise ailleurs sous la forme subintexo) : "entremêler un peu ». Dans le latin de l'époque, le préfixe sub-, " un peu », crée de très nombreux néologismes (voir René Hoven, Lexique de la prose latine de la Renaissance, Leyde, Brill, 2006, p. 529-541, de subacerbe à subuuidus). En rendant le grec hypo, le préfixe insiste ici sur l'idée de dépendance, d'ajout: subintexitur varie de façon personnelle le mot tout à fait reçu de subiungitur, « il ajoute, adjoint».

42. Fortunatianus, éd. citée : " hypodiegesis, quando quaestionem narrativo modo adprobamus » («c’è anche l'hypodieghesis (narrazione con inclusione di cause), quando dimostriamo la questione col modo narrativo »).

43. Ibid. : " catadiegesis, cum sola narratione materia continetur, quae in his controversiis conlocatur, in. quibus tota oratio narrativa est " ( c'è anche la catadieghesis (narrazione onnicomprensiva), quando nella sola narrazione è compresa la materia chè è posta in queste controversie, nelle quali tutto il discorso è narrativo »).

44. Reprise exacte de Fortunatianus, ibid. (" c'è anche l'epidieghesis (racconto), quando più ampiamente nelle questioni o prima degli epiloghi trattiamo quei fatti che nella narrazione tocchiamo brevemente »).

45. L'entrée diaskeuê du dictionnaire de Bailly mentionne en premier lieu l'arrangement d'un récit. Le pseudo-Hermogène a, dans son Traité sur l'invention, III, 10, un long développement sur la diaskeuê, conçue comme représentation, peinture des circonstances (nous remercions $\mathrm{Ch}$. Noille

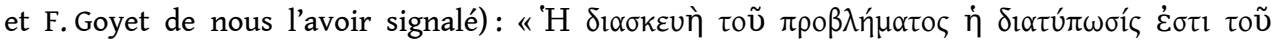

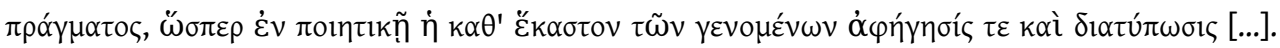

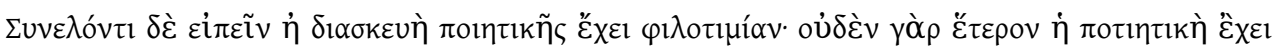

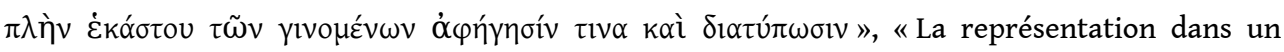
problème consiste dans la peinture de l'acte, comme en poésie elle consiste dans la représentation détaillée et la peinture de chaque événement [...] Bref, la représentation rivalise avec la poésie, car la poésie n'offre rien d'autre qu'une certaine relation et une certaine peinture

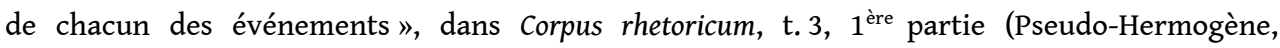
L'Invention, et Anonyme, Synopse des exordes), textes établis et traduits par Michel Patillon, Paris, les Belles Lettres, 2012, p. 66-67.

46. Reprise exacte de Fortunatianus, op. cit. («c'è anche la diasceua (costruzione), che non tanto informa sui fatti quanto li amplifica »).

47. Vu le micro-contexte, quaestio ici ne peut que désigner la quaestio infinita ou « thèse " (voir le chapitre I, 2 de J. de Jouvancy, L'Élève de rhétorique, dir. F. Goyet et D. Denis, Paris, Classiques Garnier, 2020, p. 62-65, et sur la chrie, p. 288-355). 
48. La formule est empruntée aux Tristes d'Ovide (I, I, 92), dans un tout autre contexte : « Que tu doives faire usage de la rame ou de la voile, il est difficile d'en décider d'ici : l'occasion et le lieu te guideront ", éd. et trad. J. André, Paris, Les Belles Lettres, 1968, p. 6.

49. Le texte intitulé In Helladium ou Contra Helladium, contre Hellade de Césarée, est souvent attribué à Grégoire de Nazianze, mais nous n'avons pas trouvé le passage auquel Caussin fait référence.

50. En latin : « aiunt Pyrrhum Romanos hoc praelio fudisse ». L'ambiguïté vient de ce que, dans la proposition infinitive qui dépend du verbe de parole, le sujet est à l'accusatif, de même que le COD de l'infinitif. Le latin ne marquant pas les fonctions par la place des mots, mais uniquement par les cas, il est donc impossible de savoir si le sujet de fudisse est Pyrrhum ou Romanos.

51. «[...] on trouve aussi une autre figure, qui, dépourvue de particules de coordination [coniunctionibus], est dite asyndète [dissolutio] », écrit Quintilien dans son Institution oratoire (IX, III, 50, éd. et trad.J.Cousin, Paris, Les Belles Lettres, 1978, t. V, p. 216). Comme nous l'a fait remarquer Ch. Noille, l'auteur de la Rhétorique à Herennius, loin de blâmer l'asyndète, montre l'usage que l'on peut en faire : "Cette figure a de l'efficacité. Elle est très forte et se prête bien à la concision » (IV, 41, éd. et trad. Guy Achard, Paris, Les Belles Lettres, 1989, p. 180).

52. Voir infra (n. 157), le développement que Caussin donne à ces diverses notions.

53. Timanthe de Kythnos (410-370) est un peintre grec resté célèbre par de nombreux témoignages sur sa peinture expressive, dont celui de Quintilien et de Pline l'Ancien. Quintilien, Institution oratoire, II, XIII, 13 : « Ayant à représenter le sacrifice d'Iphigénie, il avait peint Calchas triste, Ulysse encore plus triste, et donné à Ménélas le maximum d'affliction que pouvait rendre l'art; ayant épuisé tous les signes d'émotion [consumptis affectibus], ne sachant plus comment rendre convenablement l'expression du père [non reperiens quo digne modo patris vultum posset exprimere], il lui voila la tête et laissa à chacun le soin de l'imaginer à son gré [et suo quoque cuique animo dedit aestimandum]", op. cit., t. II, p. 72. Pline l'Ancien, Histoire naturelle, XXXV-XXXVI, 73 : «Pour en revenir à Timanthe, sa qualité principale fut sans doute l'ingéniosité : en effet on a de lui une Iphigénie, portée aux nues par les orateurs, qu'il peignit debout, attendant la mort, près de l'autel ; puis, après avoir représenté toute l'assistance affligée - particulièrement son oncle -, et épuisé [consumpsisset] tous les modes d'expression de la douleur, il voila le visage du père luimême, dont il était incapable de rendre convenablement les traits [patris ipsius voltum velavit, quem digne non poterat ostendere]", éd. et trad. J-M. Croisille, Paris, Les Belles Lettres, 1985. Sources citées par B. Vouilloux dans « Du figural iconique », Poétique, 2006/2, n 146, p. 131-146, ici p. 132.

54. Cicéron, Divisions de l'art oratoire, vI, 19, éd. et trad. H. Bornecque, Paris, Les Belles Lettres, 1990, p. 9. Caussin n'indique pas ici qu'il cite Cicéron.

55. Ibid.

56. Ibid. (nous avons retouché la traduction, car chez Cicéron comptum s'accorde avec genus orationis).

57. Cicéron, ibid., Ix, 31, p. 14. Nous isolons par des italiques le texte de Cicéron qui fait ensuite l'objet du commentaire (à l'inverse, Majoragius emploie ici des caractères romains, le commentaire étant chez lui en italiques). H. Bornecque traduit explicatio par exposé, mais nous préférons réserver le mot à la traduction d'expositio.

58. Le mot semble être employé ici comme synonyme de claritas.

59. Quintilien, Institution oratoire, IV, II, 119, op. cit., t. III, p. 70-71.

60. Littéralement "civile", au sens vu plus haut chez Caussin (\$222a). Ciuilis rend le grec politikos, qu'emploie précisément Aphthonios (voir note suivante).

61. "Le récit est l'exposé d'un fait réel ou donné comme tel. [...] Le récit est tantôt dramatique, tantôt historique, tantôt politique. Est dramatique le récit fictif, historique celui qui relate des faits anciens, politique celui que les orateurs emploient dans les procès", Aphthonios, 
Progymnasmata, dans Corpus rhetoricum, Paris, Les Belles Lettres, 2008, II, 2, p. 113-114. « Il s'agit là d'un best-seller pédagogique ", lit-on au sujet de l'ouvrage d'Aphthonios traduit en latin au $\mathrm{XVI}^{\mathrm{e}}$ siècle et annoté par Lorich (1542) dans J. de Jouvancy, L'Élève de rhétorique, op. cit., p. 579, note 2.

62. Cicéron, De l'invention, I, XVIII, 27, éd. et trad. G. Achard, Paris, les Belles Lettres, 1994, p. 82. Cicéron parle ici des catégories de la narration en général, et il en ajoute une troisième, « étrangère aux procédures civiles, parce qu'elle est dite et écrite pour plaire, et permet de s'entraîner d'une façon qui n'est pas inutile. » Il est logique que Majoragius l'ait omise, puisqu'il s'intéresse ici uniquement aux procédures civiles.

63. Cicéron, Pour Milon, IX, 24, op. cit., p. 93.

64. Ibid., X, 27, p. 95.

65. Ibid., IX, 25, p. 94.

66. Ibid., X, 27, p. 95.

67. Ibid., X, 29, p. 95.

68. Ibid., x, 29, p. 95-96.

69. Cicéron, Divisions de l'art oratoire, Ix, 31, op. cit., p. 14. Cicéron renvoie ici au chapitre sur l'elocutio à "formes travaillées et variées " [uersum atque mutatum], ibid., v,16, p. 8. Elle se caractérise par « les flambeaux du style, à savoir clarté [dilucidum], brièveté [breue], convenance [probabile], éclat [illustre], agrément [suaue]»: ibid., v, 19, p. 9.

70. Horace, Art poétique, v. 147. Il s'agit des deux œufs de Léda à la suite de son accouplement avec Zeus métamorphosé en cygne, et qui donneront naissance à Clytemnestre, Hélène, Castor et Pollux.

71. Quintilien, Institution oratoire, IV, II, 43 ; op. cit., t. III, p. 50-51.

72. Ibid., IV, II, 44, p. 51.

73. Aphtonios, Progymnasmata, II, 4.

74. Cicéron, Divisions de l'art oratoire, IX, 32, op. cit., p. 14.

75. Les textes de Caussin et de Majoragius divergent ici, et pour cause : il s'agit du seul endroit où Caussin allègue la source de Majoragius. Chez Caussin, le passage se situe au début du chapitre XVI de l'édition que nous avons traduite, et s'intitule « La vraisemblance de la narration tirée de quinze causes", "Narrationis probabilitas ex quindecim rebus petita». Voici comment Caussin présente le contenu de ce chapitre : «Dans cette espèce, Cicéron énumère quinze causes qui visent la vraisemblance, et celles-ci sont illustrées par Majoragius avec des exemples bien connus, qu'il ne sera pas superflu d'ajouter ici en faveur de la jeunesse ", "In specie quindecim enumerantur a Cicerone, quae ad probabilitatem spectant, et a Maioragio his uulgaribus exemplis illustrantur, quae in iuuentutis gratiam hinc subiicere non erit superuacaneum ». Majoragius apparaît comme celui qui fournit les exemples cicéroniens, alors que ce sont non seulement ses exemples, mais aussi son commentaire qui sont recopiés.

76. P. Clodius et Annius Milo sont les noms respectifs de l'acccusateur et de l'accusé en lice dans le procès de Milon : Cicéron appelle d'abord son client T. Annius (Pour Milon, op. cit., I, 1, p. 82), avant de l'appeler Milon durant tout son plaidoyer. Dans sa copie, Caussin supprime cet exemple (Parallela, op. cit., p. 223a).

77. Cicéron, Pour Sex. Roscius d'Amérie, op. cit., vi, 17, p. 6

78. Ibid., VI, 19, p. 7. Caussin supprime cet exemple (Parallela, op. cit., p. 223a).

79. Nous supprimons les parenthèses qui encadrent la citation chez Majoragius.

80. Cicéron, Pour Milon, op. cit., IX, 25, p. 94.

81. Pour Sex. Roscius d'Amérie, IX, 26, op. cit., p. 10. Caussin supprime cet exemple (Parallela, op. cit., p. 223b). 
82. Il s'agit de Caton d'Utique, qui appuie l'accusation de S. Sulpicius contre le consul Muréna, dont Cicéron est le défenseur dans le Pour Muréna. L'exemple de Caton sera également utilisé à propos de l'auctoritas, voir infra, n. 74.

83. Dans le Pour Muréna (IV, 10), Cicéron tempère ses attaques contre les accusateurs Caton d'Utique et S. Sulpicius, qui sont ses amis et ses alliés politiques. Dans l'exorde, il répond avec douceur aux griefs de Sulpicius qui lui reproche de ne pas être fidèle, dans ce procès, à leur amitié : «Ainsi ce qu'il faut accorder à l'amitié, je te l'accorderai sans réserve; j'agirai donc envers toi, Servius, comme si mon frère, qui m'est si cher, se trouvait à ta place. Quant à ce qu'il faut attribuer au devoir, à l'honneur, à la conscience, je le ferai avec modération (moderabor) en me rappelant que c'est contre les poursuites d'un ami que je défends un ami menacé " (Pour L. Muréna, dans Discours, éd. citée, t. XI, p. 36). Dans la réfutation (XXIX, 60), Cicéron représente, non sans ironie, le stoïcisme impitoyable de Caton comme une vertu trop inflexible, auquel il oppose un platonisme et un aristotélisme plus tempérés: "Quant à moi, Caton, l'estime singulière que j'ai pour ta valeur morale ne me permet pas de te reprocher ta conduite, mais sur certains points peut-être pourrais-je y apporter un ajustement et une légère correction », op. cit., p. 67. Caussin dans sa copie supprime ce développement sur le traitement par Cicéron de ses adversaires (Parallela, op. cit., p. 223b).

84. Cicéron, Pour Sex. Roscius d'Amérie, op. cit., vII, 18, p. 7.

85. Cicéron, Pour P. Quinctius, III, 12. Cet exemple est également utilisé infra pour les « dispositions morales » (habitus), voir n. 86.

86. Cicéron, Pour Caelius, IV, 9 , dans Discours, t. XV, éd. et trad. J. Cousin, Paris, Les Belles Lettres, 1969, p. 92. Cet exemple est également utilisé infra pour les "circonstances temporelles » (tempora), voir n. 102.

87. Cicéron, Pour Sex. Roscius d'Amérie, vi, 15, op. cit. p. 6.

88. Caussin supprime la définition de la « disposition morale " (habitus), ainsi que la distinction entre bonne et mauvaise disposition morale (Parallela, op. cit., p. 223b).

89. Cicéron, Pour P. Quinctius, III, 12, dans Discours, t. I, éd. et trad. H. de La Ville de Mirmont, revues par J. Humbert, Paris, Les Belles Lettres, 1960, t. I, p. 19. L'exemple est repris supra à propos des « uictus» (mode de vie), voir n. 82.

90. Cicéron, Pour Sex. Roscius d'Amérie, VI, 16, op. cit., p. 6. Dans sa copie, Caussin supprime cet exemple (Parallela, op. cit., p. 223b).

91. Cicéron, Pour Ligarius, I, 3, dans Discours, t. XVII, éd. et trad. M. Lob, Paris, Les Belles Lettres, 1968 , p. 67.

92. Ibid.

93. Cicéron, Pour le poète Archias, III, 4, Discours, éd. et trad. F. Gaffiot, Paris, Les Belles Lettres, 1989, t. XII, p. 35

94. Cicéron, Pour Sex. Roscius d'Amérie, x, 28, op. cit., p. 11.

95. Cicéron Pour Milon, IX, 24., op. cit., p. 93. Cet exemple est également employé infra, à propos de l'air antique (antiquitas), voir n. 129. Dans sa copie, Caussin supprime cet exemple (Parallela, op. cit., p. 223b).

96. Rem publicam : nous rétablissons les deux mots, abrégés en « Remp. " par Maioragius.

97. Caussin, dans sa copie, supprime la remarque « sont très souvent narrées " (« uero saepissime narrrantur ») (Parallela, op. cit., p. 223b).

98. Cicéron, Pour Milon, IX, 24., op. cit., p. 93-94.

99. Ibid., X, 27, op. cit., p. 95.

100. Cicéron, Pour Ligarius, I, 3, op. cit., p. 67.

101. Cicéron, Pour Milon, IX, 25, op. cit., p. 94.

102. Ibid., IX, 26, p. 94. 
103. Majoragius résume ici la narration du plaidoyer pour Milon qu'il vient de citer à plusieurs reprises : IX, 24-29, p. 94-96. Dans sa copie, Caussin supprime cette paraphrase (Parallela, op. cit., p. 224b).

104. Cicéron, Pour Ligarius, I, 2, op. cit., p. 67. « Cum proconsule », « avec le proconsul », est un ajout de Majoragius, que reprend Caussin.

105. Dans le Pour Caelius (IV, 10), Cicéron affirme qu'à l'époque de sa préture, Caelius était son ami, restait constamment auprès de lui et ne fréquentait jamais Catilina : Pour Caelius, op. cit., p. 92-93. Cet exemple est également utilisé supra pour le « mode de vie » (victus), voir n. 83.

106. Cicéron, Pour Milon, $x, 27$. La citation exacte est « ut ante suum fundum, quod re intellectum est, Miloni insidias collocaret. ", " pour organiser, devant un de ses domaines, un attentat contre Milon, comme l'événement l'a fait comprendre », op. cit., p. 95. Caussin reprend telle quelle cette citation inexacte de Majoragius.

107. Cicéron, Seconde action contre Verrès, livre I, XxIV, 63 (dans Discours, éd. et trad. H. de La Ville de Mirmont, Paris, Les Belles Lettres, 1984, t. II, p. 153). Ce discours était compté comme la «troisième » Verrine, la première étant le Contre Caecilius et la seconde, la Première action contre Verrès : voir le tableau dans J. de Jouvancy, L'Élève de rhétorique, op. cit., p. 45.

108. Cicéron, Pour Sex. Roscius d'Amérie, op. cit., VII, 18, p. 7. L'exemple est cité par Quintilien, également à propos de l'exposé du lieu dans la narration : IV, II, 2.

109. Cicéron, Pour Milon, x, 29, op. cit., p. 95.

110. Cicéron, Pour Milon, IX, 25, op. cit., p. 94 . Caussin ne garde que cette citation du plaidoyer pour Milon, et supprime les deux suivantes (Parallela, op. cit., p. 224a).

111. Ibid., IX, 28, « il est sans rien qui le gêne, sans bagages encombrants, n'ayant avec lui ni ses compagnons ordinaires, ni sa femme », op. cit., p. 95.

112. Ibid., XXI, 55, p. 110.

113. Il s'agit d'une réécriture libre du Pour Milon, IX, 24 : "Convocabat tribus, se interponebat, Collinam nouam dilectu perditissimorum civium conscribebat» («Il convoquait les tribus, s'entremettait, recrutait une autre tribu Colline en enrôlant les plus vils des citoyens. »), op. cit., p. 94.

114. Chez Cicéron, « nullis impedimentis » se trouve avant « nullis Graecis ».

115. Chez Cicéron, « ut solebat».

116. Cicéron, Pour Milon, IX, 26, éd. cit, p. 94-95.

117. Pour Sex. Roscius d'Amérie, XIV, 39, op. cit., p. 15.

118. Cicéron, Pour Milon, x, 29, op. cit., p. 96. La citation de Cicéron est tronquée, chez Majoragius de même que chez Caussin : "fecerunt id serui Milonis - dicam enim aperte, non deriuandi criminis causa, sed ut factum est - nec imperante domino nec sciente nec praesente, quod suos quisque seruos in tali re facere uoluisset ". "Ils se conduisirent alors, ces esclaves de Milon - je le dirai en toute franchise, non pour éluder l'accusation, mais parce que c'est ainsi que la chose s'est passée - sans que leur maître leur donnât d'ordres, sans qu'il le sût et hors de sa présence, comme chacun aurait voulu que ses esclaves se conduisissent en pareille circonstance. »

119. Pour Sex. Roscius d'Amérie, op. cit., VI, 16, p. 6.

120. Allusion à l'éloge (ambigu, voir supra, n. 80) de Caton d'Utique que Cicéron prononce dans le Pour Muréna : XXIX, 60, p. 67. L'exemple de Caton était utilisé à propos de la « natura».

121. Les narrations des Verrines sont consacrées aux crimes et à la corruption de Verrès durant sa préture en Sicile.

122. Pour Milon, IV, 10, p. 86. Dans sa copie, Caussin coupe la citation plus tôt que Majoragius, à « une loi naturelle» (« Est enim (inquit) haec, Iudices, non scripta, sed nata lex etc. », Parallela, op. cit., p. 224b).

123. Ibid., III, 9 : «Si les Douze Tables ont permis de tuer impunément un voleur, la nuit en toute occasion et le jour s'il se défendait à main armée, comment peut-on penser que, quelles que 
soient les circonstances d'un meurtre, l'auteur doit être châtié, quand on voit que parfois l'arme du meurtre nous est présentée par les lois elles-mêmes ? ", op. cit., p. 86.

124. Majoragius donne « enim » où Cicéron donne « igitur ».

125. Ibid., IX, 30, p. 96-97.

126. Ibid., $\mathrm{X}, 27$. Majoragius, et à sa suite Caussin, tronque le passage de Cicéron : «iter sollemne, legitimum, necessarium ante diem tertium decimum Kalendas Februarias Miloni esse Lanuuium ad flaminem prodendum, quod erat dictator Lanuui Milo", " Milon avait à faire à date fixe un voyage officiel et obligatoire, le treizième jour avant les calendes de février: il devait se rendre à Lanuvium pour la désignation d'un flamine, car Milon était dictateur à Lanuvium. », op. cit. p. 95.

127. Réécriture de Cicéron, Divisions de l'art oratoire, XI, 32 : « si probitas narrantis significabitur », op. cit., p. 15.

128. Aristote, Rhétorique, I, 2, 1356a1. Il s'agit du premier type de preuves techniques, dans la tripartition d'Aristote : elles "résident dans le caractère (èthos) de celui qui parle " (les deux autres types de preuve technique s'appuient sur « le fait de mettre l'auditeur dans telle ou telle disposition » (diatheinai pôs) et sur le « discours " (logos). Voici comment Aristote décrit ensuite la preuve technique par l'èthos (1356a5) : «Il y a persuasion par le caractère quand le discours est ainsi fait qu'il rend celui qui parle digne de foi. Car nous faisons confiance plus volontiers et plus vite aux gens honnêtes, sur tous les sujets tout bonnement (haplôs), et même résolument (pantelôs) sur les sujets qui n'autorisent pas un savoir exact et laissent quelque place au doute; il faut que cela aussi soit obtenu par l'entremise du discours et non en raison de l'opinion préconçue de celui qui parle. », op. cit., p. 126-127.

129. Caussin supprime la mention des mœurs de l'orateur, et fond les deux phrases : «C'est la raison pour laquelle Aristote compte aux nombres des preuves techniques les mœurs de l'orateur même, quand elles sont exprimées ", Ideo Aristoteles inter probationes artificiosas, mores etiam ipsius rei, si exprimantur, annumerat, op. cit. p. 224b.

130. Cicéron, Pour Milon, XI, 30, op. cit., p. 96.

131. Le texte de Maioragius signale «Rhétorique livre I» dans la marge, pour autoriser cette référence.

132. Cicéron, Pour Milon, IX, 24, op. cit., p. 93. Cet exemple est également utilisé supra, à propos des « décisions » (consilia), cf. n. 92.

133. Érasme commente ce proverbe dans l'adage 1274, Mendacem memorem esse oportet: http:// ihrim.huma-num.fr/nmh/Erasmus/Proverbia/Adagium_1274.html, page consultée le 10 octobre 2021.

134. Allusion à la fameuse formule de Caton: "Orator est, Marce fili, vir bonus, dicendi peritus» (fragment 14). Cette formule devenue proverbiale est notamment citée chez Quintilien : Institution oratoire, XII, I, 27.

135. Cicéron, Divisions de l'art oratoire, IX, 32, op. cit., p. 15. Nous modifions la traduction de H. Bornecque en remplaçant «qui captivent» par «qui suscitent l'attente» (quae habet expectationes) et «des passions" par «des désirs passionnés»(cupiditates). Cité par Quintilien (nous donnons son texte supra, note 7).

136. L'histoire est racontée par Cicéron dans sa troisième Philippique (II, 3): "C. César, adolescent, ou plutôt presque enfant encore, par une inspiration et une vaillance incroyables et vraiment divines, en plein déchaînement de la folie d'Antoine, alors qu'on redoutait son retour de Brindes, cruel et funeste, sans que nous l'en sollicitions, sans que nous y pensions, sans même que nous en exprimions le vœu, tant la chose semblait impossible, C. César, dis-je, a rassemblé une armée très solide, composée de cette sorte de soldats vétérans qui ne connaît pas la défaite ; il a prodigué son patrimoine; non, je ne me suis pas servi du terme qui s'impose : il ne l'a pas prodigué, c'est un placement qu'il a fait sur le salut de l'État » (Discours, Philippiques I à IV, éd. et trad. A. Boulanger et P. Wuilleumier, Paris, Les Belles Lettres, 1959, t. XIX, p. 166). 
137. Ibid., p. 193.

138. Cicéron, Pour Cluentius, vI, 15 , Discours, t. VIII, éd. et trad. P. Boyancé, Paris, Les Belles Lettres, 1974, p. 68.

139. Ibid., XXVIII, 75 , p. 104.

140. Ibid., v, 12, p. 66 .

141. Majoragius s'appuie ici, sans l'expliciter, sur Quintilien (Institution oratoire, IX, II, 22), qui observe le goût de Cicéron pour les digressions et les préparations dans les Verrines, identifiées comme un procédé de sustentatio (suspension) : «Parfois, dans de telles formes de communication $<$ avec l'auditoire> nous ajoutons quelque chose d'inattendu, ce qui est déjà en soi une figure, comme le fait Cicéron dans les Verrines: Et alors? Qu'en pensez-vous? Peut-être un vol ou un pillage? puis, après avoir tenu longtemps en suspens l'esprit des juges, il suggère quelque chose de beaucoup plus malhonnête. C'est ce que Celsus appelle suspension [sustentatio]», op. cit., t. v, p. 175-176. Le passage de Cicéron cité par Quintilien se trouve dans la Seconde action contre Verrès, livre V, v, 10. Sur la théorisation de la suspension dans les rhétoriques antiques, voir L. Charles, Les Promesses du roman. Poétique de la prolepse sous l'Ancien Régime (1600-1750), Paris, Garnier, 2021, p. 341-371.

142. Caussin recopie avec excellentes, et non excellentis comme dans l'édition des Belles Lettres, dont nous faisons figurer ici la traduction. On pourrait donc traduire : « il y a dans la destinée éminente, variée et mouvementée d'un homme... ».

143. Voir Cicéron, Lettre à Luccéius, Fam. V, XII, 5, Correspondance, tome II, éd. et trad. L.A. Constans, Paris, les Belles Lettres, 1950, p. 161.

144. Majoragius cite un peu plus loin (voir n. 148) le passage d'Aristote sur le plaisir suscité par la colère. Ici, il paraphrase donc très probablement ce qui suit immédiatement : « Un certain plaisir accompagne la plupart des désirs » (Aristote, Rhétorique, I, 11, 1370b15), qu'il a lui-même traduit en latin par « maximam cupiditatum partem voluptas quaedam consequitur » et commenté par "In omni fere cupiditate, inquit, inest aliqua voluptas» (Majoragius, In tres Aristotelis libros de Arte Rhetorica [...] Explanationes, Venise, Fr. Franciscius, 1572, f. 82v, colonne de gauche, incipit du commentaire sur ce passage). Chez Aristote, le passage intervient juste après les fameuses considérations du chapitre sur le plaisir (iucunditas ou uoluptas dans la trad. Majoragius) que procurent l'espoir et la colère, qui sont deux « passions » ou animi motus emblématiques. Merci à F. Goyet pour cette note.

145. Sassia était la mère de Cluentius Habitus. Elle a fait divorcer son gendre pour l'épouser.

146. Cicéron, Pour Cluentius, op. cit., V, 12-13, p. 67.

147. Cicéron, Seconde action contre Verrès, livre I, XXVI, 66, op. cit., p. 155-156.

148. Nous rectifions l'édition de Majoragius, qui porte " filiam trium ».

149. Cicéron, Pour Sex. Roscius d'Amérie, IX, 24, op. cit., p. 86.

150. Cicéron, Pour Cluentius, op. cit., v, 13, p. 67-68.

151. Caussin dans sa copie supprime la référence à Aristote « ut citat Aristotelis »: Parallela, op. cit., p. 225 a.

152. Aristote, Rhétorique, II, 1378b5-7 (nous passons les termes au féminin pour les accorder avec colère, tandis que P. Chiron les accorde avec emportement). Aristote cite ici les v. 109-110 de l'Iliade (t. III, éd. Paul Mazon, avec Pierre Chantraine, Paul Collart et René Langumier, Paris, Les Belles Lettres, 1961, p. 171). Le passage d'Aristote se présente sous la forme d'un syllogisme : « Car il est doux de croire qu'on va obtenir ce qu'on poursuit ; mais personne ne poursuit des choses qui lui sont manifestement impossibles et l'homme en colère poursuit des choses qui lui sont possibles. D'où la justesse de ce mot sur l'emportement... », op. cit., p. 265. Notons que les auteurs grecs font du sentiment de colère une source de plaisir, parce que l'homme en colère imagine déjà sa vengeance, tandis que Majoragius traite ici de la colère représentée, et éprouvée par procuration.

153. Cicéron, Pour Sex. Roscius d'Amérie, IX, 24, op. cit., p. 86. 
154. Ibid.

155. Cicéron, Seconde action contre Verrès, livre I, XXVI, 67, op. cit., p. 156.

156. Cicéron, Pour Cluentius, v, 14, op. cit., p. 68.

157. Cicéron, Seconde action contre Verrès, livre I, XXVI, 66, op. cit., p. 155.

158. Cicéron, Pour Sex. Roscius d'Amérie, $x, 29$, op. cit., p. 72.

159. Cicéron, Pour Cluentius, VI, 18, op. cit., p. 70.

160. Caussin, qui a repris littéralement tout ce qui précède, ajoute ici un développement qui rappelle la brève notice sur l'asyndète (supra, § 223a, n. 49), et qui reprend Cicéron, sans mentionner cette source : « En ce qui concerne les mots, "l'agrément du style tiendra d'abord au choix et à l'agrément de mots sonores et harmonieux, puis à leur assemblage, qui n'offrira pas d'aspérités, de trous ou d'hiatus ; qui formera une période bien arrondie, non pas trop longue dans son contour, mais en rapport avec la puissance du souffle; qui présentera dans les mots quelque ressemblance et quelque symétrie" " («In uerbis suaue genus erit dicendi, primum elegantia, et iucunditate uerborum sonantium, et leuium, deinde coniunctione, quae neque asperos habeat concursus, neque disiunctos, atque hiantes, et sit circumscripta non longo anfractu, sed ad spiritum uocis apto, habeatque similitudinem, aequalitatemque uerborum. »), Divisions de l'art oratoire, VI, 21, p. 10.

\section{AUTEURS}

\section{LISE CHARLES}

Sorbonne Université

SUZANNE DUVAL

Université Gustave Eiffel 